This is the final peer-reviewed accepted manuscript of:

Luca Landi, Annalisa Tardini \& Pier Paolo Diotallevi (2016) A Procedure for the Displacement-Based Seismic Assessment of Infilled RC Frames, Journal of Earthquake Engineering, 20:7, 1077-1103

The final published version is available online at:

https://doi.org/10.1080/13632469.2015.1112324

Rights / License:

The terms and conditions for the reuse of this version of the manuscript are specified in the publishing policy. For all terms of use and more information see the publisher's website.

This item was downloaded from IRIS Università di Bologna (https://cris.unibo.it/)

When citing, please refer to the published version. 


\title{
A Procedure for the Displacement-Based Seismic Assessment of Infilled RC Frames
}

Luca Landi, Annalisa Tardini, Pier Paolo Diotallevi

Department DICAM -University of Bologna, Bologna, Italy.

\begin{abstract}
The aim of this study was to propose an extension of the displacement-based assessment procedure for infilled reinforced concrete (RC) frames. Two fundamental steps of the displacement-based approach were studied: the determination of the equivalent viscous damping and the definition of the limit-state displacement profile. The proposed criteria were derived by examining the results of two different numerical investigations regarding the nonlinear seismic response of single and multi-storey infilled RC frames. Lastly, the effectiveness of the method was verified through comparisons, in terms of displacement demand, with the results of nonlinear dynamic analyses.
\end{abstract}

Keywords: Infilled Frames, Equivalent Strut Model, Non Linear Dynamic Analysis, Equivalent Viscous Damping, Displacement-Based Assessment

\section{Introduction}

Many existing buildings, such as those in Italy, are built using RC frames with masonry infill. Various studies [Klingner and Bertero, 1978; Bertoldi et al., 1993; Comité Euro-International Du Béton, 1996; Al-Chaar, 2002, Cavaleri et al., 2003 and 2005; Decanini et al., 2004; Crisafulli and Carr, 2007; De Sortis et al., 2007; Amato et al., 2008; Dolsek and Fajfar, 2008;

Corresponding author: Luca Landi; email: 1.landi@,unibo.it; Phone +39 051 2093245, Fax +39 0512093236 
Smyrou et al., 2011] showed how the presence of masonry infills may alter the overall behaviour of structures when subjected to seismic action. These studies focused on different aspects, as the modelling approaches for evaluating the effects of infill panels and the verification of the models with experimental results. Some studies were dedicated also to experimental tests on real multi-storey RC frames [Negro et al., 1995; Pinto et al., 1999]. Other numerical and experimental researches faced the important issues of controlling the in-plane damage of masonry infills by defining drift limits associated to different limit states [Calvi and Bolognini, 2001; Hak et al., 2012; Morandi et al., 2014].

The presence of masonry infills can produce either positive or negative effects [StaffordSmith, 1961; Mainstone, 1971; Fardis and Panagiotakos, 1997; Negro and Colombo, 1997; Asteris, 2003; El-Dakhakhni et al., 2003; Korkmaz et al., 2007], and, in the former case, it can increase the strength and the dissipative capacity of the structure while, in the latter, it can produce irregularities or negative local interactions with $\mathrm{RC}$ elements. However, the most widespread and established practices of building design do not consider infills as structural elements, ignoring their strength and stiffness. Current codes as Eurocode 8 [CEN, 2003] do not provide criteria for the calculation of the infill strength while they give rules against possible negative effects. For the aforementioned reasons, in analytical models, these elements are often neglected, except their contribution in terms of mass and vertical load. This is possibly not the correct choice, especially when evaluating existing RC structures or during the subsequent selection and design of retrofit strategies [Landi et al., 2014a].

This study investigated the seismic assessment procedures for infilled RC frames, where the requirement was, first, to define a proper model for the nonlinear seismic analysis of infilled RC frames. An equivalent strut model proposed in literature [Al-Chaar, 2002; Cavaleri et al., 2003] was developed using specific software and calibrated through comparisons with available experimental results for cyclic loading [Landi et al., 2013].

In particular, the aim of the research was to propose an extension of the Displacement-Based Assessment (DBA) procedure for infilled RC frames [Priestley et al., 2007]. The displacementbased design approach [Priestley et al., 2007] is based on the schematization of a general 
structure, such as a linear single-degree of freedom (SDOF) system characterized by secant stiffness at maximum displacement and a level of equivalent viscous damping. The same approach is followed when carrying out the seismic assessment of existing buildings. Using the assessment method, it is possible to determine the displacement demand to be compared with the displacement capacity. The displacement demand can be determined by an iterative procedure that involves calculating the equivalent damping of the structure. This calculation can be performed using the relations between ductility and equivalent damping proposed in literature, which depends on the various types of structure [Iwan and Gates, 1979; Judi and Fenwick, 2001; Dwairi et al., 2007; Priestley et al., 2007; Pennucci et al., 2011]. Recently some authors [Sullivan et al., 2014] proposed a solution to the iterative nature of the DBA process to converge to a given limit state intensity via the use of a ductility-damping relationship to create inelastic spectra to quickly estimate system displacements for multi-intensity assessments. Considering bare frames only may lead to an underestimation of the dissipative capacity of the structure and hysteretic damping. So the first objective of this research was to identify the criteria to define a ductility-damping law able to account for the presence of the infills [Landi et al., 2012]. In order to determine the above relationship, several nonlinear dynamic analyses were carried out by applying different ground motions to single storey-single bay infilled frames.

In the displacement-based approach, the equivalence between a SDOF and a multi-degree of freedom (MDOF) system is based upon knowing the limit-state displacement profile. Therefore, the second objective of this research was to study the criteria for deriving the displacement profile for infilled frames. To reach this objective, several nonlinear pushover and dynamic analyses were performed on a group of different infilled multi-storey RC frames. These analyses allowed the determination of the response in terms of base shear-top displacement and to investigate the configuration of collapse. In particular, the lateral displacement profile at collapse and the plastic hinge distribution were both examined. From these results, it was possible to propose a method to predict the collapse displacement profile for infilled frames. In the DBA, in fact, being able to predict the displacement profile is a fundamental aspect 
[Priestley et al., 2007; Benedetti et al., 2014]. In the performed analyses it was assumed that the considered case studies do not manifest problems related to bar slip or to local failures in the joints, which can be present in certain types of existing buildings. However their influence on the determination of the expected inelastic mechanism can be included in the assessment procedure as suggested by Sullivan and Calvi [2011] for bare RC frames.

The final objective of this research was to verify the effectiveness of the proposed DBA method for infilled frames. This was performed through comparisons, in terms of displacement demand, with the results of nonlinear dynamic analyses of multi-storey frames.

\section{The model for infilled RC frames}

This section provides a brief description of the characteristics and calibration of the model used for the infilled RC frames in numerical investigations. For more details, see Landi et al. [2013]. The model was implemented using OpenSees software [McKenna and Fenves, 2005]. A distributed plasticity model with fibre sections was used for the RC frames [Diotallevi and Landi, 2006; Landi et al., 2014b]. The elements of the RC frames were modelled using a single finite element for each beam or column. Five control sections were used for each element. A bilinear stress-strain relationship with hardening and the Bauschinger effect was used for the steel fibres. The concrete was modelled using a constitutive law that includes stiffness and strength degradation due to cyclic loading. The cover concrete and the concrete core were assigned different types of behaviour. In the first case, the effect of confinement was not considered; in the second case, it was included, according to the model proposed by Mander et al. [1988]. In all the models of the tested frames, an element was added at the top of the columns to account for possible shear failure in the column, due to its interaction with the infill. This is a zero length element with shear strength equal to that of the column. The shear strength of the columns was evaluated according to the modified UCSD model [Priestley et al., 1996; Kowalsky and Priestley, 2000; Priestley et al., 2007]. 
The infill panels were modelled using a system with two equivalent struts, as suggested by numerous authors in literature [Bertoldi et al., 1993; Al-Chaar, 2002; Klingner and Bertero, 1978; Cavaleri et al., 2003; Amato et al., 2008; Decanini et al., 2004]. Each masonry strut was considered to be effective only in compression. The models proposed by Al-Chaar [2002] and by Cavaleri et al. [2005] were used, where the model suggested by the former was used for its monotonic behaviour, and that proposed by the latter for its cyclic response. The width and strength of the struts were calculated according to the Al-Chaar model. The infill panels were implemented in the OpenSees (Open System for Earthquake Engineering Simulation) software using a truss element that works only for axial stress. The stress-strain law of the strut was determined according to the axial force-displacement response derived from the Al-Chaar model (Figure 1). In order to complete the modelling of the strut, it was necessary to examine its cyclic behaviour, defining the parameters to determine strength degradation and the loading and unloading branches. To apply the model proposed by Cavaleri et al. [2005] it was necessary to calibrate these parameters through comparisons with experimental results. Two experimental tests were considered. The first was conducted by the National Laboratory of Civil Engineering (LNEC) and is available in Pires [1990], the second was carried out by Colangelo [2004].

Initially, it was necessary to determine the points that define the monotonic material behaviour assigned to the strut, as shown in Figure 1b. In particular, the problem was to identify how the constitutive law changes after yielding, as a consequence of the strength degradation shown in the masonry. For this purpose, the slope of the second branch and the residual strength were altered to obtain a force-displacement response from the analytical model close to the envelope curve of experimental tests. The examined structures were subjected to a lateral force in a single direction because the force-displacement envelope curve was the only one being considered. Once the analyses were carried out, the constitutive law that agreed best with the experimental results is the one shown in Figure $1 \mathrm{~b}$. This law is defined by a residual strength equal to $25 \%$ of the peak strength and by a softening branch slope equal to $2 \%$ of the initial stiffness. 
The cyclic behaviour was analyzed using a hysteretic constitutive law implemented in the OpenSees software for the truss element. This law is defined by three parameters relating to the definition of the unloading and reloading branches. These parameters, which regulate the degradation of the unloading stiffness and the pinching effect, were calibrated so that the analytical model could provide a cyclic behaviour as close as possible to the one indicated by Cavaleri et al. [2005] and to the experimental results. In Figure 2, the numerical results obtained with the calibrated values of these parameters are compared to the experimental ones [Pires, 1990; Colangelo, 2004]. From the figure, it is possible to observe that there is good agreement between the numerical and experimental results.

\section{Equivalent viscous damping for infilled frames}

The equivalent damping is given by the sum of two contributions, the inherent damping, normally taken as $5 \%$ for all types of structures, and hysteretic damping, which depends on the dissipative capacity of the different structures. As the hysteretic damping is a measure of the dissipative capacity of structures in the inelastic range, it is expected to be larger for RC frames with masonry infills than for bare frames. This difference will be larger for small values of ductility demand. Due to the deterioration of the infills, the values of hysteretic damping of infilled and bare frames are, on the contrary, expected to be similar with the increase of ductility demand. The objective of this section was to evaluate the equivalent damping of infilled frames, with the purpose of obtaining criteria to define a ductility-damping law able to account for the presence of the infills.

\subsection{Procedure for the evaluation of the equivalent damping}

As previously mentioned, various ductility-damping laws were proposed in literature, depending on the type of structure being examined. In particular, the following relationship was proposed for the design of new RC bare frames [Priestley et al., 2007]:

$$
\xi_{e q}=0,05+0,565\left(\frac{\mu-1}{\mu \pi}\right)
$$


where $\mu$ represents the structure ductility demand. The aim was to define a relationship valid for infilled frame similar to Eq. (1). In order to determine the equivalent damping, several nonlinear dynamic analyses were carried out using different ground motions and considering single storey-single bay frames. This choice was made in order to have a simple model useful to perform a large number of analyses. It should be also considered that for an existing building it is likely to have a column-sway mechanism with the global inelastic response mainly affected by the response of a single storey. Moreover, the effectiveness of the ductility-damping law can be verified a posteriori by application to multi-storey frames, as illustrated in the last section. The analyses were repeated for bare and infilled frames in order to compare the two sets of responses. The adopted procedure can be summarised in the following steps:

1. Apply ground motion to the structure and determine the force-displacement response.

2. Identify the maximum displacement $\left(\delta_{\max }\right)$ caused by the ground motion and relative ductility $\mu$, calculated with reference to the yield displacement.

3. Determine the secant stiffness $K_{\text {sec }}$ corresponding to the maximum displacement (Figure 3a) and then calculate the relative period $T_{\text {sec. }}$.

4. Identify the reduced displacement spectrum relative to the considered earthquake record that intercepts the point $\left(T_{s e c}, \delta_{\max }\right)$ (Figure $\left.3 \mathrm{~b}\right)$ and determine the corresponding damping. In this way, it is possible to obtain one couple of ductility-damping values valid for this single examined case.

5. Steps 1-4 are repeated using the same earthquake record scaled to different values of intensity. In this way, several couples $\mu-\xi$ are obtained.

6. The entire procedure is repeated using different ground motions.

7. All the results are interpolated in order to obtain an expression defining the ductilitydamping relation.

This analysis was performed for values of ductility demand for the bare frame of less than 5 . This is the range of values in which the infills may affect the seismic response. The ductility 
was elaborated using the yield displacement of the bare frame. This displacement was calculated using the following expression of yield drift proposed in literature [Priestley et al., 2007]:

$$
\theta_{y}=0,5 \varepsilon_{y} \frac{L_{b}}{h_{b}}
$$

where $\varepsilon_{y}$ is the steel yield strain, while $L_{b}$ and $h_{b}$ are, respectively, the length and the depth of the beam. The use of Eq. (2) for the portal frames considered in the analysis, and described in the following section, is related to the fact that their beams and columns have similar moment capacities, and that the occurrence of plastic hinges in columns is accompanied by that in beams. It should be noted that the ductility of the infilled frame was also calculated with reference to the yield displacement of the bare frame. This choice was made considering the possibility of obtaining a ductility-damping law to be applied when very little is known about the response of the infilled frame, or when it is based directly on the characteristics of the bare frame only, even when there are infills. If it is possible to refer directly to the yield displacement of the bare frame, the yield displacement of the infilled frame need not be known. Moreover, using the yield displacement of the infilled frame would only change the scale of value. Once the maximum displacement was determined for each ground motion, two cases were examined, according to the secant stiffness used to calculate the period. In the first case, the secant stiffness considered was the one relating to the monotonic force-displacement response of the bare frame $\left(K_{\text {bare }}\right)$, while, in the second case, it was the one relating to the monotonic force-displacement response of the infilled frame $\left(K_{i n f}\right)$. This distinction was examined with the purpose of evaluating whether it is necessary to know some aspects of the response for the infilled frame or if it is enough to know that of the bare frame. In Figure 4, it is possible to see the two different stiffnesses relating to the force-displacement response of the bare and infilled frames.

\subsection{Examined cases: structures under study and performed analyses}

The procedure being described was applied to three different single storey-single bay RC frames (Frames 1, 2 and 3). Each was considered with and without infills. All the frames have the same geometrical dimensions (Figure 5a) and contain the same amount of steel. As a consequence, 
they have the same lateral strength (Figure 5b). They also have different masses and therefore different elastic periods, as shown in Table 1. The assumed mechanical properties of the materials are: concrete cylinder strength $f_{c k}$ equal to $28 \mathrm{Mpa}$ and steel yield strength $f_{y k}$ equal to $450 \mathrm{Mpa}$. The dimensions determined for the beams are: width equal to $300 \mathrm{~mm}$ and depth equal to $500 \mathrm{~mm}$. The dimensions determined for the columns are: width and depth equal to 300 $\mathrm{mm}$. The infills being considered are masonry panels with a thickness of $150 \mathrm{~mm}$, compressive strength of $4.1 \mathrm{~N} / \mathrm{mm}^{2}$ and shear strength of $0.3 \mathrm{~N} / \mathrm{mm}^{2}$. Figure 5 shows the base sheardisplacement curves of the bare and infilled frames.

The nonlinear dynamic analyses of the considered structures were carried out using two sets of ground motions (Set_1, Set_2). The first group consists of 7 accelerograms, including four recorded and three artificial ground motions. These records, used in previous studies [Benedetti et al., 2008] on displacement-based approaches, were selected in order to have an average displacement spectrum with a corner period of $4 \mathrm{sec}$. The second group consists of 5 recorded accelerograms frequently used in literature [Landi et al., 2014a]. The properties of Set_2 records are listed in Table 2. Both groups of ground motions are consistent with type 1 Eurocode 8 [CEN, 2003] design spectrum. The displacement spectra related to the two sets of ground motions are illustrated in Figure 6. These accelerograms were applied with different intensity values in order to obtain ductility demand values of up to 5 .

\subsection{Results of the analyses}

Each single nonlinear dynamic analysis provided a value of ductility demand and equivalent or hysteretic damping and, therefore, a point in the ductility-damping diagram. All the analyses led to a series of points. From these points, it was possible to construct the average curves, which are shown with a red dotted line in the following graphs (Figure 7). Each curve reproduces the results of all the structures under study (Frame 1, 2, 3) and selected ground motions. A hyperbolic ductility damping law according to the following expression, consistent with Eq. (3), was then determined in order to best approximate the average results: 


$$
\xi_{\text {byst }}=C\left(\frac{\mu-\alpha}{\mu \pi}\right)
$$

In Eq. (3),$C$ and $\alpha$ represent two coefficients that have to be calibrated. In particular, $\alpha$ is the intersection point of the curve with the horizontal axis corresponding to hysteretic damping equal to 0 , and $C / \pi$ is the damping value for ductility tending to infinity. This type of relationship was originally proposed by Dwairi et al. [2007]. The resulting hyperbolic curve represents the desired ductility-damping law and is shown in the graphs as a continuous green line. The results of the infilled frames are illustrated through two cases distinguished by the types of stiffness considered in the procedure: the secant stiffness of the bare frame and the secant stiffness of the infilled frame. The two cases led to different values of damping. When the stiffness of the infilled frame was considered, the analysis was extended to ductility values of less than 1. The infilled frames, in fact, were defined by a hysteretic damping even for these values of ductility. However, it was meaningful to assess this damping only with the stiffness of the infilled frame, because, in several analyses that included the stiffness of the bare frame, the values of damping for low values of ductility were found to be greater than 1 . When the stiffness of the infilled frame was considered, the hyperbolic curve was constructed using two different methods. The first (A) was the same used in the other cases and led to a hyperbolic curve valid for values of ductility larger than 1; the second (B) consisted in searching for a curve close to the average results and defined by an intersection with the horizontal axis at a value of $\alpha$ less than 1: the lowest value that this parameter can take corresponds to the ratio between the yield displacement of the infilled frame and that of the bare frame.

The following relationship was obtained in the cases examined for the bare frames:

$$
\xi_{\text {hyst }}=0,794\left(\frac{\mu-1}{\mu \pi}\right)
$$

The following relationship was obtained for the infilled frames, where the stiffness of the bare frame $\left(K_{\text {bare }}\right)$ was considered in the procedure:

$$
\xi_{\text {hyst }}=0,804\left(\frac{\mu+0,83}{\mu \pi}\right), \mu \geq 1
$$


The following relationships were obtained for the infilled frames, taking account, in the procedure, of the stiffness of the infilled frame $\left(K_{i n f}\right)$ and using methods A and B:

$$
\begin{aligned}
& \xi_{\text {hyst }}=0,804\left(\frac{\mu+0,05}{\mu \pi}\right), \mu \geq 1, \text { method A } \\
& \xi_{\text {hyst }}=0,83\left(\frac{\mu-0,07}{\mu \pi}\right), \mu \geq 0, \text { method B }
\end{aligned}
$$

It is clear that the derived ductility-damping curves are affected by the characteristics of the frames being examined and by the selected ground motions. The Figure 8 shows the curves obtained for the bare frame compared with the curve proposed in literature and given in Eq. (1). In this figure, it could be observed that the curves obtained are defined by larger ordinates than that of Eq. (1); very likely, this relates to the number of examined cases. The curve of Eq. (1) was determined after considering a large number of structures, subjected to hundreds of ground motions [Priestley et al., 2007].

With regard to the infilled frames, the average curves obtained from the analyses are shown in Figure 9. Firstly, we can note that, using the stiffness of the bare frame, the hysteretic damping resulted greater than that obtained using the stiffness of the infilled frame. The nonlinear dynamic analyses carried out were the same in the two cases. The only difference was the secant stiffness used in calculating the period. With the same displacement, but using a larger stiffness, similar to the one of the infilled frame, a shorter period was obtained. In this way, the displacement spectrum passing through the new identified point $\left(T_{s e c}, \delta_{\max }\right)$ corresponded to lower damping. Figure 9 shows that the difference between the two cases decreases for increased values of ductility. This happens because, with the increase of ductility, the contribution of the infill decreases and the two stiffnesses tend to coincide. For small values of ductility, for example less than 2, the difference between the two cases is, however, significant. For these values of ductility and considering the stiffness of the bare frame, the obtained values of damping are very high because the difference between the response of the infilled frame and that of the bare frame is great. In Figure 9b, where the stiffness of the infilled frame is considered, it can be seen that the average curves obtained with the two methods A and 
B are very similar for values of ductility larger than 1. Finally, Figure 10 shows the comparison between the overall average curves for the examined cases. It can be seen that, for high values of ductility, hysteretic damping curves for the bare and infilled frames tend to converge, because the contribution of the infill tends to be erased.

We could try to find a general relationship for the infilled frame using the coefficient $C$ for the bare frame (defined in Eq. (4) or that of Eq. (1)) and the coefficient $\alpha$ from Eq. (7). In this way, the ductility-damping law would be conservative, because it would determine a lower damping value than the average value determined by the analyses carried out in this study, even when taking into account the increase in damping for small values of ductility due to the presence of the infill. Considering, for example, the value of $C$ of Eq. (4), the expression of this law is:

$$
\xi_{\text {byst }}=0,794 \frac{\mu-0,07}{\mu \pi}
$$

\section{Nonlinear seismic analysis of multi-storey infilled RC frames}

\subsection{Examined cases: structures under study and performed analyses}

Using the model previously described, several pushover and nonlinear dynamic analyses of existing frames were carried out, in order to study the mechanisms of failure and the displacement profile. The analyses were performed on bare and infilled RC frames to evaluate how the masonry panel could modify the collapse mechanism. The bare frame being examined is a five-storey three-bay symmetrical structure designed only for gravity loads. The dimensions determined for the beams are: width equal to $300 \mathrm{~mm}$ and depth equal to $500 \mathrm{~mm}$. The dimensions determined for the columns are variable and are indicated in Figure 11. The assumed mechanical properties of materials are: concrete cylinder strength $f_{c k}$ equal to $25 \mathrm{MPa}$ and steel yield strength $f_{y k}$ equal to $430 \mathrm{MPa}$. In the nonlinear model, a hardening ratio equal to 0.005 was adopted for the steel. The parameters of the confined concrete law, determined using the relationship proposed by Mander et al., [1988], were variable depending on the cross- 
section and the transverse reinforcement of columns. Notably the values obtained for the different columns are similar each other. Considering the top external columns, the confined concrete cylinder strength was equal to $31.1 \mathrm{MPa}$ and the ultimate strain was equal to about 0.01 .

With reference to the beams and columns, the infilled frame was assumed to be identical to the bare frame. Two types of masonry were examined: the masonry of the infilled frame VAR has a compressive strength of $4.1 \mathrm{~N} / \mathrm{mm}^{2}$ and shear strength of $0.3 \mathrm{~N} / \mathrm{mm}^{2}$; the masonry of the infilled frame UNIF has a compressive strength of $3.3 \mathrm{~N} / \mathrm{mm}^{2}$ and shear strength of $0.2 \mathrm{~N} / \mathrm{mm}^{2}$. Furthermore, the infilled frame VAR has masonry panels of variable thicknesses between 240 $\mathrm{mm}$ and $150 \mathrm{~mm}$; while, for the infilled frame UNIF, masonry panels are all of the same thickness of $150 \mathrm{~mm}$. The main parameters of the stress-strain law (Fig. 1b) of the equivalent struts for the considered infill masonry typologies are reported in Table 3. As shown in Figure 11, three cases were examined for both types of infilled frames: totally infilled frame, totally infilled frame with square openings of $1500 \mathrm{~mm}$ in all the panels, infilled frame without panels at the ground floor. The presence of the openings in the masonry panels was accounted for in the model through a reduction factor of the width of the diagonal strut. This factor depends on the ratio between the size of the openings and that of the infill [Al-Chaar, 2002].

The objective of these analyses was to determine the response of the structures in terms of base shear-top displacement and to evaluate their collapse displacement. At this displacement, the configuration of collapse was examined by observing the distribution of the plastic hinges and the displacement profile. In this study, the collapse was defined according to three criteria:

a) achieving the ultimate strain in the confined concrete of the columns;

b) achieving the ultimate inter-storey displacement;

c) achieving the ultimate shear strength in a structural element (beam or column).

The type of collapse "a" was associated to the first occurrence, in a confined concrete fibre, of the ultimate strain. The second type of collapse was defined by the maximum inter-storey displacement determined for each floor. This displacement was established by using the ultimate drift multiplied by the storey height. The ultimate drift was calculated as the sum of the 
yield $\left(\theta_{y}\right)$ and the plastic $\left(\theta_{P}\right)$ drifts. The yield drift was calculated with the expression proposed in literature [Priestley et al., 2007] and reported in Eq. (2). This equation was used considering that at yielding, anyway, some plastic hinges were expected to form in beams and that the ratios of element length to section depth of beams and columns are similar. The obtained yield drift, equal about to 0.01 , resulted in being the same for all the storeys. The plastic rotation capacity of the plastic hinges was determined with Eq. (9):

$$
\theta_{p}=\left(\phi_{l s}-\phi_{y}\right) L_{p}
$$

where $\phi_{l s}, \phi_{y}$ are, respectively, the limit-state and yielding curvatures and $L_{p}$ is the plastic hinge length, calculated as in [Priestley et al., 2007]. In the determination of the ultimate drifts, the considered limit state was the collapse, and $\phi_{l s}$ corresponded to the ultimate curvature, obtained from a moment-curvature analysis including the effect of confinement on the ultimate concrete strain. The calculated plastic drift was different for external and internal columns. For this reason, the ultimate drift at each storey was assumed to be the lesser between that of the external columns and that of the internal columns. The obtained yielding and ultimate curvatures of internal columns, the plastic drifts of internal columns and the ultimate drifts are shown in Table 4. Once the ultimate drift was determined, the maximum displacement was then calculated.

As discussed in the introduction, various studies proposed drift limits to control the damage of infill panels for different limit states. In particular, in the design of new buildings according to EC8, an additional limit for the ultimate limit state was proposed [Hak et al., 2012] with the purpose to enhance the infill response and to avoid risks to persons. With regard to this aspect, it should be observed that the in-plane damage of the infills associated to given performances could correspond to values of in-plane drifts less than the displacement capacities related to the performance criteria of the RC structure. This could imply that the in-plane damage on the infills could be activated before the occurrence of any limit state on the RC frame and therefore the buildings could sustain smaller values of peak ground accelerations. In the present study the evaluation of the existing building was performed referring to the collapse limit state and the collapse condition was defined on the basis of the displacement capacities of the RC structure 
only. Hence, the previous observation, together with this assumption, should be taken into consideration when examining the obtained results on the collapse acceleration of the infilled structures.

The pushover analyses were carried out using two set of forces, the first with forces proportional to the masses multiplied by the first modal deformations, and the second with forces proportional to the masses. The displacements associated to the collapse conditions were identified for each analysis. In correspondence of these displacements, the plastic hinges were observed and the displacement profile represented. This procedure made it possible to find out which mechanism of collapse occurred. The nonlinear dynamic analyses were performed using three accelerograms (here S1, S2, S3): each ground motion was applied with increasing values of intensity until the failure of the structure was reached (incremental dynamic analyses). These three accelerograms are recorded ground motions defined by an average displacement spectrum consistent with type 1 Eurocode 8 design spectrum. For each application of a single ground motion, the maximum top displacement and the maximum base shear were obtained and, therefore, a point in the base shear-top displacement diagram defined. Once a point was determined for each dynamic analysis, it was possible to derive a base shear-top displacement curve. Then, for each ground motion, it was possible to determine the intensity that caused the first occurrence of each collapse condition. At the collapse condition, the distribution of plastic hinges and the maximum displacement profile were evaluated. The nonlinear dynamic analyses were carried out only for the bare frame and for the totally infilled frame.

\subsection{Results of the analyses}

Because of the large number of results obtained, only those relating to the type of collapse "b" are illustrated in detail. This type of collapse is the most significant, as usually it is associated with a column-sway mechanism. We noted that collapse "a" was reached for smaller displacements than collapse "b" in all the analyses we carried out, as is shown in Figure 12. Collapse "c", associated with achieving the ultimate shear strength, never occurred. In the considered frame, in fact, a limited amount of longitudinal reinforcement was required in the 
columns for gravity loads. As a consequence, the flexural strength of the columns was low and was reached before the shear failure.

The results of the pushover analyses are shown in Figure 12. In general, these results show that the contribution of the infill, in terms of base shear, was significant only for a displacement lower than about $75 \mathrm{~mm}$. For larger displacements, as those associated to collapse "b", the infills of the collapsed storeys exceeded the deformation at $25 \%$ of peak stress and their strength was significantly reduced. The collapse of the infilled frames always occurred at displacements smaller than those of the bare frame. However, for a given distribution of forces, the mechanism of collapse of the infilled and the bare frame always occurred at the same storey. Furthermore, the results relative to the infilled frame show that the presence of openings did not substantially modify the response of the frame. The openings simply reduced the lateral strength of the structure. The absence of infills at the ground floor produced, as expected, a collapse mechanism at the first storey. We could finally see that the presence of infill did not change the mechanism of collapse, but affected the displacement profile. In the examined cases, the collapse occurred at the first or the third floor for both the bare and the infilled frames, while the displacement profile for the infilled frames had lower values than that of the bare frame (Figure 13). This was linked with the plastic hinges which, in the infilled frames, were concentrated at the storey of collapse. With this distribution of plastic hinges, the collapse displacement was close to the ultimate displacement of the single storey, without significant effects of the deformation of the other storeys.

In the results obtained from the nonlinear dynamic analyses (Figure 14), the infilled frames had greater strength but a lower collapse displacement than the bare frames. This is similar to the result obtained in the pushover analyses. However, in the nonlinear dynamic analyses, there was a more widely spread distribution of plastic hinges for the infilled frames at all storeys than for the pushover analyses. For such frames, the top displacement was influenced not only by the inter-storey displacement where the collapse occurred, but also by the inter-storey displacements of two other storeys. As a consequence of the observed distribution of plastic hinges, the displacement profiles of the infilled frames were found to be more similar to the 
profile of the bare frame than the results of the pushover analyses. Figure 15 shows, for example, the results relative to accelerogram S1 being applied.

Using incremental dynamic analyses, it was possible to evaluate the peak ground acceleration (PGA) at the collapse. In Table 5, the values of the peak ground acceleration are illustrated for the different cases and collapse conditions examined. In particular, the table shows the average values of the three accelerograms. For all cases, the seismic input necessary to reach the collapse of the infilled frame resulted to be larger than that required for the bare frame. It could be seen that the average values relative to the infilled frame are about $70 \%$ greater than those relative to the bare frame for collapse "a" and about $40 \%$ greater for collapse "b". This result is related to the reduction of the displacement demand for the infilled frames when compared to that for the bare frame.

\section{Proposal of a procedure for the DBA of infilled RC frames}

This section illustrates a proposal for an extension of the displacement-based assessment procedure [Priestley et al., 2007; Sullivan and Calvi, 2011] for infilled RC frames. As it is known, according to the displacement-based approach, a general MDOF structure is schematized by an equivalent linear SDOF system defined by the secant stiffness at maximum displacement and by equivalent damping. The ductility-damping laws previously derived for infilled frames were implemented in the procedure together with a proposed method to predict the collapse mechanism and the displacement profile. The procedure was then applied to the multi-storey frames described in section 4 , and its effectiveness was tested through comparisons with the results of nonlinear dynamic analyses.

\subsection{Description of the assessment procedure for MDOF structures}

The DBA procedure extended to infilled RC frames is summarized in the steps reported in the following: each step is described with reference to the study cases in section 4 .

1. Assess the moment-curvature response of the structural elements. 
2. Determine the plastic rotation capacity of the plastic hinges, for the considered limit state, according to Eq. (9).

3. Assume the expected inelastic mechanism. This mechanism can be defined on the basis of simple evaluations of particular indices, or, alternatively, on the basis of the results of pushover analyses. In the first case, Prietsley and Calvi [1991] and, more recently, Priestley [1997] and Priestley et al. [2007], proposed the calculation of a sway potential index, which provides an approximate indication whether a beam-sway or a column-sway inelastic mechanism is to be expected. This index, relating to the relative strength of beams and colums, is calculated at a given floor $i$ as follows:

$$
S_{i}=\frac{\sum_{j=1}^{n j}\left(M_{B j, l}+M_{B j, r}\right)}{\sum_{j=1}^{n j}\left(M_{C j, b}+M_{C j, a}\right)}
$$

where $M_{B j, l}, M_{B j, r}$ are the beam flexural strengths at the left and right of the joint, respectively, and $M_{C j, b}, M_{C j, a}$ are the column flexural strengths above and below the joint. All the mentioned moments are extrapolated to the joint centroid. The beam and column moments are summed over the $n j$ joints in the frame at the floor level considered. If $S_{i}$ is greater than 1.0 a column-sway mechanism is expected. If $S_{i}$ is less than 1.0 a beam-sway mechanism could be expected, but Priestley et al. [2007] observed that if $S_{i}$ is greater than 0.85 it would be reasonably conservative to assume a column-sway mechanism, given the uncertainties in the assessment. The possibility of forming shear mechanisms should also be checked by comparing the member shear demand in presence of flexural plastic hinges at each end of a member, with the member shear resistance [Sullivan et al., 2014]. The calculation of the sway potential index was performed for the considered bare frame. The obtained values, shown in Table 6, suggest the possible occurrence of a column-sway mechanism at least from the second to the last floor. As observed in previous section, the mentioned condition for shear failure are not verified for the case under study. 
4. In the case of column-sway mechanism, identify which floor the mechanism is most likely. To this purpose it is possible to calculate at each storey the sway demand index $S D_{i}$ as proposed by Sullivan and Calvi [2011] and Welch et al. [2014]:

$$
S D_{i}=\frac{V_{i, d e m}}{V_{i, R}} \frac{V_{\text {base }, R}}{V_{\text {base }, \text { dem }}}
$$

where $V_{i, d e m}$ and $V_{i, R}$ are, respectively, the storey shear demand and resistance at level $i$, and $V_{\text {basedem }}$ and $V_{\text {base, } R}$ are the base shear demand and resistance respectively. The values of storey and base shear demand can be evaluated once a distribution of lateral forces is assumed. Their ratio can be obtained with Eq. (12):

$$
\frac{V_{i, \text { dem }}}{V_{\text {base,dem }}}=\frac{\sum_{k=i}^{n} F_{k}}{V_{\text {base,dem }}}
$$

where $F_{k}$ is the lateral force to be applied at the level $k$ in the assumed lateral force distribution. The shear resistance at a storey $i$ can be obtained as:

$$
V_{i, R}=\frac{\sum_{j=1}^{n c}\left(M_{C j, b}+M_{C j, t}\right)}{H_{i-1 i}}
$$

where $M_{C j, b}$ and $M_{C j, t}$ are the column moment capacities at the bottom and top of the columns, $H_{i-1 i}$ is the inter-storey height and the sum is made over all the $n c$ columns of the storey $i$. Observe that the higher the sway-demand index, the higher the likelihood of a column-sway mechanism forming. So, the most likely mechanism to occur is that at the storey with the greatest value of $S D_{i}$. The base shear at the formation of this mechanism can be obtained by dividing the base shear resistance, the one associated to the strength of the columns at the base, by the value of $S D_{i}$. In the case of an infilled frame, if a ductilitydamping law based on the stiffness of the bare frame is used, and the strength of the infills is not evaluated, a possible hypothesis, depending on the distribution of infill panels and the type of RC structure, could be to assume the mechanism of the infilled frame similar to that of the corresponding bare frame. Alternatively, if a ductility-damping law based on the stiffness of the infilled frame is used, and the strength of the infills is considered, the total 
shear at the collapsed storey should be determined by also including the shear strength of the infill panels $V_{i n f}$ :

$$
V_{i, R}=\frac{\sum_{j=1}^{n c}\left(M_{C j, b}+M_{C j, t}\right)}{H_{i-1 i}}+V_{i n f}
$$

The shear strength of the infill panels can be evaluated with any capacity model for the infills. In the examined cases, the same model was used in the nonlinear analyses and in the application of Eq. (14). The calculation of the sway demand indices for the identification of the mechanism and the corresponding base shear was then performed for the bare and infilled frames under study. Since a degrading monotonic law was considered for the infills, in this calculation the shear strength of the infill panels was evaluated in two different ways: considering the peak strength $\left(V_{\max }\right)$ or considering the residual strength, equal to $25 \%$ of the peak strength $\left(V_{25 \%}\right)$. The obtained values of $S D_{i}$ are shown in Table 6 while the estimates of base shear associated to the sway mechanisms at the different storeys are reported in Table 7. These values were derived assuming the same distribution of lateral forces as in the pushover analysis (first mode lateral forces). It is possible to notice that for both infilled frames VAR and UNIF, and for both values of infill strength, $V_{\max }$ and $V_{25 \%}$, the greatest value of $S D_{i}$ was obtained for the mechanism at the third storey, as for the bare frame. This result corresponds to the one obtained in the pushover analysis (first mode lateral forces), thus showing that the followed approach was effective. It is possible to notice also that the peak base shear obtained from the pushover analysis is included between the estimates derived with $V_{\max }$ and $V_{25 \%}$ (Fig. 12(b)). At the formation of the mechanism the infill panels of the third storey had already exceeded the strain associated to the peak stress.

5. Define the limit-state displacement profile .For the bare frame, the limit-state displacement profile can be defined, as proposed in literature [Priestley et al., 2007], by adding yield displacement to the plastic displacement. The storey displacement at yield can be assumed to be linear along the height, and can be determined as the product of the yield rotation with 
the height. For the aforementioned reasons, the drift derived from Eq. (2) was used to obtain the yield profile of the examined bare frame. Note that for the bare frame, despite the occurrence of column sway mechanisms, the nonlinear static and dynamic analyses confirmed the formation of several hinges in beams at different levels (see Fig. 13(a) and Fig. 14(a)). In this context it should be mentioned that some researchers proposed relationships based on column rather than beam properties, specific for gravity designed RC frames characterized by column-sway collapse. An example is the relationship proposed by Glaister and Pinho [2003] and utilised in Sullivan and Calvi [2011], where the coefficient 0.5 in Eq. (2) is replaced by 0.43 and the span length and beam depth become the inter-storey height and column depth respectively. Assuming a column swaymechanism at the floor at which collapse occurs (level $i$ ), the plastic displacement may be calculated as:

$$
\Delta_{P}=\theta_{P} H_{i-1 i}
$$

where $\theta_{P}$ is the lower of the plastic rotation capacity of the columns at level $i$. The limitstate displacement is thus obtained by adding the yield displacement to the plastic displacement at the levels above the one in which the collapse occurs. Below this level, the limit-state displacement corresponds to the yield displacement. Regarding the infilled frame, a new method was adopted for this study. In particular, the method is based on defining the values of yield displacements of the infilled frame as a fraction of the yield displacements of the corresponding bare frame and is based on the assumption of a given collapse mechanism of the infilled frame, as from the previous steps. This method was then studied and applied to the study cases presented previously. Initially, the displacement profile obtained from pushover analyses, for both bare and infilled frames, was observed. In particular, the displacement profile observed at the instant before the column-sway mechanism occurred was assumed to be the yield displacement profile. The displacement profiles obtained from pushover analyses are the ones represented by dotted lines in Figure 16. In order to linearize the displacement profile, a ratio was calculated between the 
displacement from pushover analysis of the infilled frame and the displacement of the bare frame, for each floor. The mean of the values obtained for these ratios at each level was then applied to the values of yield displacement. A mean ratio equal to 0.18 was derived for the infilled frame VAR, while a value equal to 0.44 was obtained for the infilled frame UNIF. The linear displacement profile determined in this way was assumed to be the yield displacement of the infilled frame (continuous lines in Figure 16). In terms of the limitstate displacement profile (Figure 17), the procedure used was the same used for the bare frame, and the yield displacement was added to the plastic displacement at the levels above the one at which the collapse occurred. In Figure 18, the limit-state displacement profiles obtained from pushover analyses are compared to those obtained using the proposed procedure.

6. Define the equivalent SDOF system. As it is known, the parameters that define the equivalent SDOF system are the equivalent mass and effective height [Priestley et al., 2007]:

$$
\begin{aligned}
& m_{e}=\frac{\left(\sum_{i=1}^{n} m_{i} \Delta_{i}\right)^{2}}{\sum_{i=1}^{n} m_{i} \Delta_{i}^{2}} \\
& H_{e}=\frac{\sum_{i=1}^{n} m_{i} \Delta_{i} H_{i}}{\sum_{i=1}^{n} m_{i} \Delta_{i}}
\end{aligned}
$$

where $m_{i}$ is the mass at level $i$, while $H_{i}$ and $\Delta_{i}$ are, respectively, the height and the displacement of the mass $m_{i}$. In the case being assessed, the displacement at a level $i$ can be assumed to correspond to that at the limit-state. The yield displacement $\Delta_{y}$ of the equivalent SDOF system can be derived as:

$$
\Delta_{y}=\theta_{y} \cdot H_{e}
$$

7. Determination of the displacement demand for the equivalent SDOF system $\left(\Delta_{d e m, \mathrm{SDOF}}\right)$ : this calculation can be performed following the iterative procedure described in Priestley et 
al. [2007] and using the ductility-damping laws for infilled frames. As previously illustrated, different types of laws were proposed for performing the assessment on the basis of the stiffness of the bare frame or considering the stiffness of the infilled frame.

8. Transform the displacement demand for the SDOF structure in the displacement demand for the MDOF structure. The effectiveness of the method was verified by comparing the displacement demand obtained from nonlinear dynamic analyses for the study cases with the displacement obtained in the assessment procedure. Once the assessment of the SDOF structure was carried out, the displacement demand $\Delta_{d e m, \text { SDOF }}$ was determined. It was then necessary to determine the displacement demand at the top of the five storey frame being considered. The relation between the displacement demand for the equivalent SDOF structure and the displacements at the different levels $\Delta_{d e m, i}$ can be written as:

$$
\Delta_{d e m, \mathrm{SDOF}}=\frac{\sum_{i=1}^{n} m_{i} \Delta_{d e m, i}^{2}}{\sum_{i=1}^{n} m_{i} \Delta_{\operatorname{dem}, i}}
$$

In this case, the unknown terms are the displacements of the storeys. However, in the nonlinear range, considering a prefixed column-sway mechanism, all these displacements depend upon a single parameter, the plastic rotation of the yielded columns. Therefore, an inverse expression of Eq. (19) was used to determine the plastic rotation associated to the displacement demand. By knowing this rotation, it was then possible to derive the displacement demand at each storey.

\subsection{Examined cases}

The procedure above was applied to the selected bare and infilled frames. Regarding the infilled frames, different cases were examined. In particular, two different seismic intensities were analysed, one with peak ground acceleration equal to $0.53 \mathrm{~g}$ and the other with PGA equal to $0.74 \mathrm{~g}$. The two cases of stiffness previously mentioned were also examined. In the first case, the stiffness of the infill panels was neglected and the base shear was obtained considering only the RC frames $\left(K_{\text {bare }}\right)$. In the second case, the stiffness of the infills was considered and the base 
shear was obtained, which also included the shear strength of the infill panels $\left(K_{\text {inf }}\right)$. In this last case, as seen in step 4, the shear strength of the infill panels was evaluated in two different ways: considering the peak strength $\left(V_{\max }\right)$ or considering the residual strength $\left(V_{25 \%}\right)$. All the analyses were repeated for the two different infilled frames denominated VAR and UNIF.

\subsection{Results}

At the end of the analyses, for each case being examined, it was possible to compare the displacement obtained with the DBA procedure with the displacement obtained from nonlinear dynamic analyses. Tables 8 and 9 show all the results in terms of top displacement, together with the corresponding ductility and damping values. It is possible to note that the estimates obtained with the DBA procedure were close to the results of the nonlinear dynamic analyses, except when $V_{\max }$ was considered. The agreement between the proposed DBA and nonlinear dynamic analyses was very good, especially when $K_{i n f}$ and $V_{25 \%}$ were considered. In these cases, the estimate obtained with DBA was almost always conservative. In Figure 19, the estimates obtained in these cases, together with the results of the nonlinear dynamic analyses, are shown superimposed on the pushover curves. The estimates obtained considering $V_{\max }$ were not very close to the results of the nonlinear dynamic analyses, since the responses of the infilled frames, for the considered seismic intensities, largely over-passed the peak point (see Fig. 19). The estimates obtained when considering the stiffness of the bare frame for the infilled frames were not conservative, but they were, however, quite good and not overly different to the results of nonlinear dynamic analyses, especially for PGA=0.74 g.

When the stiffness of the infilled frame was assumed in the assessment, DBA was repeated for comparison, first applying the law in Eq. $(7)\left(C_{i n f}\right)$, and then the law in Eq. $(8)\left(C_{b a r e}\right)$. The difference between the results obtained using Eqs. (7) or (8) was not particularly significant. With Eq. (8), the results of DBA were always conservative, and, as expected, more conservative than when using Eq. (7). 


\section{Conclusion}

The analyses of the infilled frames revealed several difficulties that were due above all to the many variables concerning masonry infill models. In order to solve these difficulties, the comparison with experimental results was fundamental. By carrying out this comparison, it was possible to calibrate an equivalent strut model for the infills.

The first investigation allowed the determination of the ductility-damping laws to be used in the displacement-based assessment of existing infilled frames. These laws could be useful, since they are applicable even when not all the aspects of the response of the infilled frames are known in detail. In this way, it could be possible to account for the infill mainly in terms of dissipation. It is clear that, in order to make a generalization of the obtained laws, the performed analyses must be repeated for a larger number of frames and ground motions. A possible simple law of general validity was also proposed.

The study continued with a series of nonlinear analyses of infilled multi-storey frames. The initial aim was to determine the response of the structures in terms of base shear-top displacement curve and to evaluate the limit-state displacement profile. The distribution of plastic hinges and the displacement profile were analysed under collapse conditions. In this way, it was possible to determine the type of collapse mechanism. The results obtained show that the presence of the infills increased the response significantly in terms of strength and stiffness. All the analyses showed a collapse of the infilled frame at displacements smaller than those of the bare frames. This result was related to the distribution of plastic hinges, which, in the infilled frames, were more concentrated near the collapsed storey. Furthermore, the larger stiffness and strength of the infilled structures caused a reduction of the displacement demand. For this reason, the examined infilled frames were able to sustain larger peak ground accelerations than the bare frames. It should be observed that this result was derived considering case studies with no detrimental effects of the infills, as irregularities or negative local interactions, and referring to a collapse limit state without additional limitation for controlling 
the damage of the infills. The obtained results are then preliminary and need further developments regarding the issue of the in-plane damage control of the infills.

On the basis of the performed analyses, a simplified method was proposed to predict the displacement profile of infilled frames under yield and collapse conditions. This method, together with the ductility-damping laws obtained, was implemented in the displacement-based assessment procedure, and subsequently applied to the examined cases. In verifying the proposed DBA for infilled frames, it showed a good agreement with the results of nonlinear dynamic analyses.

\section{Acknowledgements}

This research was developed with the contribution of the Italian national project DPC - ReLUIS 2010-2013 (Thematic Area 2, Research Line 2).

\section{References}

Al-Chaar, G. [2002] Evaluating strength and stiffness of unreinforced masonry infill structures, US Army Corps of Engineers, Engineer Research and Development Center.

Amato, G., Cavaleri, L., Fossetti, M. and Papia, M. [2008] "Infilled frames: influence of vertical load on the equivalent diagonal strut model", Proceedings of the 14th World Conference on Earthquake Engineering. Beijing, China.

Asteris, P. G. [2003] "Lateral stiffness of brick masonry infilled plane frames", Journal of Structural Engineering, 129(8), 1071-1079

Benedetti, A., Landi, L. and Malavolta, D. [2008] "On the design and evaluation of seismic response of RC buildings according to direct displacement-based design approach," Proceedings of the 14th World Conference on Earthquake Engineering Beijing, China.

Benedetti, A., Landi, L. and Merenda, D. G. [2014] "Displacement-based design of an energy dissipating system for seismic upgrading of existing masonry structures," Journal of 
Earthquake Engineering 18(4), 477-501.

Bertoldi, S. H., Decanini, L. D. and Gavarini, C. [1993] "Telai tamponati soggetti ad azioni sismiche. Un modello semplificato. Confronto sperimentale e numerico", Proceedings of the 6th National Conference ANIDIS, Perugia, Italy.

Calvi, G. M. and Bolognini, D. [2001] "Seismic response of RC frames infilled with weakly reinforced masonry panels," Journal of Earthquake Engineering 5(2),153-185.

Cavaleri, L., Fossetti, M. and Papia, M. [2003] "Infilled frames: developments in the evaluation of the stiffening effects of infill”, Structural Engineering and Mechanics 16, 675-693.

Cavaleri, L., Fossetti, M. and Papia, M. [2005] "Infilled frames: developments in the evaluation of cyclic behaviour under lateral loads", Structural Engineering and Mechanics 21, 469494.

CEN [2003] Eurocode 8. "Design of Structures for Earthquake Resistance - Part 1: General Rules, Seismic Actions and Rules for Buildings”, Brussels.

Colangelo, F. [2004] "Pseudo-dynamic seismic response of infilled RC frames designed for gravity load", Proceedings of the 13th World Conference on Earthquake Engineering Vancouver, Canada.

Comité Euro-International Du Béton [1996] RC frame under earthquake loading. State of the art report, Thomas Telford Publishing, London.

Crisafulli, F. J. and Carr, A. J. [2007] "Proposed macro-model for the analysis of infilled frame structures", Bulletin of the New Zealand Society of Earthquake Engineering 40(2), 69-77.

De Sortis, A., Bazzurro, P., Mollaioli, F. and Bruno, S. [2007] "Influenza delle tamponature sul rischio sismico degli edifici in calcestruzzo armato", Proceedings of the 12th National Conference ANIDIS, Pisa, Italy.

Decanini, L., Mollaioli, F., Mura, A. and Saragoni, R. [2004] “Seismic performance of masonry infilled R/C frame", Proceedings of the 13th World Conference on Earthquake Engineering, Vancouver, Canada. 
Diotallevi, P.P. and Landi, L. [2006] "Response of RC structures subjected to horizontal and vertical ground motions", $8^{\text {th }}$ U.S. National Conference on Earthquake Engineering, San Francisco, California, USA.

Dolsek, M. and Fajfar, P. [2008] "The effect of masonry infills on the seismic response of a four-storey reinforced concrete frame - A deterministic assessment”, Engineering Structures 30, 1991-2001

Dwairi, H.M., Kowalsky, M.J. and Nau, J.M. [2007] "Equivalent Damping in Support of Direct Displacement-Based Design,” Journal of Earthquake Engineering 11(4), 512-530.

El-Dakhakhni, W.W., Elgaad, M. and Hamid, A.A. [2003] "Three-strut model for concrete masonry-infilled steel frames", Journal of Structural Engineering 129(2), 177-185.

Fardis, M. and Panagiotakos, T. [1997] "Seismic design and response of bare and masonryinfilled RC buildings. PART II: infilled structures", Journal of Earthquake Engineering 1(3), 475-503.

Glaister, S. and Pinho, R. [2003] "Development of a simplified deformation-based method for seismic vulnerability assessment," Journal of Earthquake Engineering, 7(S1),107-140.

Hak, S., Morandi, P., Magenes, G. and Sullivan, T. [2012] "Damage control for clay masonry infills in the design of RC frame structures," Journal of Earthquake Engineering 16(S1), 135.

Iwan, W. and Gates, N. [1979] "The effective period and damping of a class of hysteretic structures," Earthquake Engineering and Structural Dynamics 7, 199-211.

Judi, H., Fenwick, R. and Davidson, BJ. [2001] "Direct displacement based design-a definition of damping", Proceedings of the 2001 NZSEE Technical Conference. Auckland, New Zealand.

Klingner, R. and Bertero, V. [1978] "Earthquake resistance of infilled frames”, Journal of the structural division 104, 973-989.

Korkmaz, K. A., Demir, F. and Sivri, M. [2007] "Earthquake assessment of R/C structures with 
masonry infill walls", International Journal of Science and Technology 2(2), 155-164.

Kowalsky, M.J. and Priestley, M.J.N. [2000] “An improved analytical model for shear strength of circular RC columns in seismic regions", ACI Journal 97(3), 388-396.

Landi, L., Lucchi, L. and Diotallevi, P.P. [2014a] "A procedure for the direct determination of the required supplemental damping for the seismic retrofit with viscous dampers." Engineering Structures 71, 137-149.

Landi, L., Pollio, B. and Diotallevi, P.P. [2014b] "Effectiveness of different standard and advanced pushover procedures for regular and irregular RC frames", Structural Engineering and Mechanics 51(3), 433-446.

Landi, L., Tardini, A. and Diotallevi, P.P. [2012] "Equivalent viscous damping for the displacement-based seismic assessment of infilled RC frames", Proceedings of the 15th World Conference on Earthquake Engineering, Lisbon.

Landi, L., Tardini, A. and Diotallevi, P.P. [2013] "Nonlinear seismic analysis of infilled RC frames with an equivalent strut model", Proceedings of the ECCOMAS Thematic Conference - COMPDYN 2013: 4th International Conference on Computational Methods in Structural Dynamics and Earthquake Engineering, Kos Island, Greece, 12-14 June.

Mainstone, R. [1971] "On the stiffness and strength of infilled frames", Proceedings of the Institution of Civil Engineers, London, Supplement IV, Paper 7360S, 57-90.

Mander, J., Priestley, M. and Park, R. [1988] "Theoretical stress-strain model for confined concrete," Journal of Structural Engineering 114, 1804-1825.

McKenna, F. and Fenves, G. [2005] Open System for Earthquake Engineering Simulation, University of California, Berkley.

Morandi, P., Hak S. and Magenes, G. [2014] "In-plane Experimental Response of Strong Masonry Infills", Proc. of the 9th International Masonry Conference, Guimarães, Portugal, 7-9 July.

Negro, P., Anthoine, A., Combescure, D., Magonette, G., Molina, J., Pegon, P. and Verzeletti, 
G. [1995] "Tests on Four-Storey Full-Scale Reinforced Concrete Frame with Masonry Infills: Preliminary Report”, Special publication No. I.95.54, European Commission, Joint Research Centre, Ispra, Italy.

Negro, P. and Colombo, A. [1997] "Irregularities induced by non-structural masonry panels in framed buildings", Engineering Structures 7(7), 576-585.

Pennucci, D., Sullivan, T.J., and Calvi, G.M. [2011] "Displacement Reduction Factors for Design of Medium and Long Period Structures," Journal of Earthquake Engineering 15(S1), 1-29.

Pinto, A., Verzelletti, G., Molina, F.J., Varum, H., Carvalho, E.C. and Coelho, E. [1999] "Pseudo-Dynamic Tests on Non-Seismic Resisting RC Frames (Infilled Frame and Infill Strengthened Frame Tests),” EU Special Publication, Joint Research Centre, Ispra, Italy.

Pires, F. [1990] Influencia das paredes de alvenaria no comportamento de estruturas reticuladas de betao armado sujeitas a accoes horizontais, Specialist Thesis, LNEC, Lisbon.

Priestley, M.J.N. [1997] "Displacement-Based Seismic Assessment of Reinforced Concrete Buildings," Journal of Earthquake Engineering 1(1), 157-192.

Priestley, M.J.N. and Calvi, G.M. [1991] "Towards a capacity-design assessment procedure for reinforced concrete frames," Earthquake Spectra 7(3), 413-437.

Priestley, M.J.N., Seible, F. and Calvi, G.M. [1996] Seismic Design and Retrofit of bridges, Wiley, New York.

Priestley, M.J.N., Calvi, G.M. and Kowalsky, M.J. [2007] Displacement-Based Seismic Design of Structures, IUSS Press, Pavia.

Smyrou, E., Blandon, C., Antoniou, S., Pinho, R. and Crisafulli, F. [2011] "Implementation and verification of a masonry panel model for nonlinear dynamic analysis of infilled RC frames”, Bulletin of Earthquake Engineering 9(5), 1519-1534.

Stafford-Smith, B. [1961] "Behaviour of square infilled frames", Journal of the Structural Division ASCE, 91, 381-403. 
Sullivan, T. and Calvi, G.M. [2011] "Considerations for the Seismic Assessment of Buildings Using the Direct Displacement-Based Assessment Approach", Proceedings of the 14th National Conference ANIDIS, Bari, Italy.

Sullivan, T.J., Welch, D.P. and Calvi, G.M. [2014] "Simplified seismic performance assessment and implications for seismic design," Earthquake Engineering and Engineering Vibration, 13, 95-122.

Welch, D.P., Sullivan, T.J. and Calvi, G.M. [2014] "Developing Direct Displacement-Based Procedures for Simplified Loss Assessment in Performance-Based Earthquake Engineering," Journal of Earthquake Engineering, 18(2), 290-322. 


\section{LIST OF TABLES}

Table 1. Properties of the examined single-storey single-bay frames.

\begin{tabular}{cc}
\hline & $T$ elastic [s] \\
\hline Frame 1 & 0.35 \\
Frame 2 & 0.50 \\
Frame 3 & 1.00 \\
\hline
\end{tabular}

Table 2. Set_ 2 ground motions for the nonlinear dynamic analyses.

\begin{tabular}{lcclcc}
\hline Location & Year & Ms & Station & Name & PGA $[\mathrm{g}]$ \\
\hline Chile & 1985 & - & El Almendral & ELAL & 0.284 \\
Imperial Valley & 1940 & 7.0 & El Centro & ELCE & 0.348 \\
Northridge & 1994 & 6.7 & Newhall & NEWH & 0.583 \\
Montenegro & 1966 & - & Petrovac & PETR & 0.438 \\
Kern County & 1952 & 7.4 & Taft & TAFT & 0.178 \\
\hline
\end{tabular}

Table 3. Parameters of the constitutive law of the equivalent strut.

\begin{tabular}{|c|c|c|c|c|c|}
\hline & Panels & $E_{i}[\mathrm{MPa}]$ & $\sigma_{\text {peak }}[\mathrm{MPa}]$ & $\varepsilon_{\text {peak }}$ & $\varepsilon_{0.25 \text { peak }}$ \\
\hline \multirow{4}{*}{ 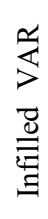 } & Lateral, storey 1-2 & 12300 & 2.65 & $2.16 \cdot 10^{-4}$ & $8.90 \cdot 10^{-3}$ \\
\hline & Lateral, storey 3-5 & 12300 & 2.73 & $2.22 \cdot 10^{-4}$ & $8.86 \cdot 10^{-3}$ \\
\hline & Central, storey $1-2$ & 12300 & 2.34 & $1.90 \cdot 10^{-4}$ & $7.64 \cdot 10^{-3}$ \\
\hline & Central, storey 3-5 & 12300 & 2.32 & $1.89 \cdot 10^{-4}$ & $8.09 \cdot 10^{-3}$ \\
\hline \multirow{4}{*}{ 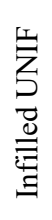 } & Lateral, storey 1-2 & 9900 & 1.65 & $1.67 \cdot 10^{-4}$ & $6.53 \cdot 10^{-3}$ \\
\hline & Lateral, storey 3-5 & 9900 & 1.73 & $1.75 \cdot 10^{-4}$ & $7.09 \cdot 10^{-3}$ \\
\hline & Central, storey 1-2 & 9900 & 1.48 & $1.50 \cdot 10^{-4}$ & $6.29 \cdot 10^{-3}$ \\
\hline & Central, storey 3-5 & 9900 & 1.51 & $1.53 \cdot 10^{-4}$ & $6.29 \cdot 10^{-3}$ \\
\hline
\end{tabular}

Table 4. Yielding and limit state curvatures of internal columns, plastic drifts of internal columns and limit state drifts

\begin{tabular}{cccccc}
\hline Storey & $L_{p}[\mathrm{~m}]$ & $\phi_{y}\left[\mathrm{~m}^{-1}\right]$ & $\phi_{l s}\left[\mathrm{~m}^{-1}\right]$ & $\theta_{p}$ & $\theta_{l s}$ \\
\hline 5 & 0.32 & 0.006 & 0.210 & 0.065 & 0.075 \\
4 & 0.32 & 0.007 & 0.159 & 0.049 & 0.059 \\
3 & 0.32 & 0.007 & 0.101 & 0.030 & 0.040 \\
2 & 0.32 & 0.007 & 0.087 & 0.026 & 0.036 \\
1 & 0.32 & 0.006 & 0.068 & 0.020 & 0.030 \\
\hline
\end{tabular}


Table 5. Values of peak ground acceleration at the collapse condition.

\begin{tabular}{ccccc}
\hline & & $\begin{array}{c}\text { PGA }[\mathrm{g}] \text { for } \\
\text { bare frame }\end{array}$ & $\begin{array}{c}\text { PGA }[\mathrm{g}] \text { for infilled frame } \\
\text { VAR }\end{array}$ & $\begin{array}{c}\text { PGA [g] for infilled frame } \\
\text { UNIF }\end{array}$ \\
\hline $\begin{array}{c}\text { Collapse "a" } \\
\left(\varepsilon_{\text {cu }}\right)\end{array}$ & $\mathrm{S} 1$ & 0.408 & 0.680 & 0.612 \\
& $\mathrm{~S} 2$ & 0.268 & 0.540 & 0.469 \\
& $\mathrm{~S} 3$ & 0.260 & 0.455 & 0.520 \\
& average & 0.312 & 0.558 & 0.534 \\
\hline \multirow{2}{*}{$\begin{array}{c}\text { Collapse "b" } \\
\left(\Delta_{u, \text { inter }}\right)\end{array}$} & $\mathrm{S} 1$ & 0.544 & 0.748 & 0.952 \\
& $\mathrm{~S} 2$ & 0.502 & 0.670 & 0.737 \\
& $\mathrm{~S} 3$ & 0.585 & 0.715 & 0.780 \\
& average & 0.544 & 0.711 & 0.823 \\
\hline
\end{tabular}

Table 6. Sway potential indices and sway demand indices for the considered case studies.

\begin{tabular}{ccccccc}
\hline \multirow{2}{*}{ Storey } & \multirow{2}{*}{$\begin{array}{c}S_{i} \text { Bare } \\
\text { frame }\end{array}$} & $\begin{array}{c}S D_{i} \text { Bare } \\
\text { frame }\end{array}$ & \multicolumn{2}{c}{$\begin{array}{c}S D_{i} \text { Infilled frame } \\
\text { VAR }\end{array}$} & \multicolumn{2}{c}{$S D_{i}$ Infilled frame } \\
\cline { 4 - 7 } & & & $V_{\max }$ & $V_{25 \%}$ & $V_{\max }$ & $V_{25 \%}$ \\
\hline 5 & 4.21 & 0.850 & 0.438 & 0.595 & 0.454 & 0.651 \\
4 & 1.81 & 1.408 & 0.899 & 1.122 & 0.902 & 1.178 \\
3 & 1.37 & 1.499 & 1.177 & 1.338 & 1.137 & 1.355 \\
2 & 1.04 & 1.300 & 1.063 & 1.179 & 1.131 & 1.234 \\
1 & 0.81 & 1.000 & 1.000 & 1.000 & 1.000 & 1.000 \\
\hline
\end{tabular}

Table 7. Estimates of base shear associated to sway mechanisms at different storeys.

\begin{tabular}{cccccc}
\hline \multirow{2}{*}{ Storey } & \multirow{2}{*}{$\begin{array}{l}V_{\text {base }} \text { Bare } \\
\text { frame [kN] }\end{array}$} & \multicolumn{2}{c}{$V_{\text {base Infilled frame }}$ VAR [kN] } & \multicolumn{2}{c}{$V_{\text {base Infilled frame }}$ UNIF [kN] } \\
\cline { 3 - 6 } & 710 & 3509 & 1404 & 2232 & 1085 \\
\hline 5 & $V_{\max }$ & $V_{25 \%}$ & $V_{\max }$ & $V_{25 \%}$ \\
4 & 428 & 1709 & 745 & 1124 & 599 \\
3 & 402 & 1305 & 625 & 892 & 522 \\
2 & 464 & 1445 & 709 & 896 & 572 \\
1 & 603 & 1536 & 836 & 1014 & 706 \\
\hline
\end{tabular}


Table 8. Comparison between DBA and nonlinear dynamic analyses (DYN): PGA $=0.53 \mathrm{~g}$.

\begin{tabular}{|c|c|c|c|c|c|c|}
\hline & & $\mu$ & $\xi_{e}$ & $\mathrm{DBA}[\mathrm{mm}]$ & $\mathrm{DYN}[\mathrm{mm}]$ & $\Delta_{\mathrm{DBA}} / \Delta_{\mathrm{DYN}}$ \\
\hline$\stackrel{\mathscr{Z}}{\mathscr{n}}$ & Kbare & 2.32 & $19 \%$ & 340 & 322 & $106 \%$ \\
\hline \multirow{5}{*}{ 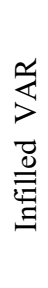 } & Kbare & 0.53 & $52 \%$ & 79 & 115 & $69 \%$ \\
\hline & $K_{i n f,} V_{\max }, C_{i n f}$ & 0.20 & $22 \%$ & 35 & 115 & $30 \%$ \\
\hline & $K_{\text {inf }}, V_{\max }, C_{\text {bare }}$ & 0.21 & $22 \%$ & 37 & 115 & $32 \%$ \\
\hline & $K_{i n f}, V_{25 \%}, C_{i n f}$ & 0.75 & $29 \%$ & 105 & 115 & $91 \%$ \\
\hline & $K_{\text {inf }}, V_{25 \%}, C_{\text {bare }}$ & 0.91 & $23 \%$ & 126 & 115 & $110 \%$ \\
\hline \multirow{5}{*}{$\begin{array}{l}\text { 岂 } \\
\text { Z } \\
\text { 导 } \\
\stackrel{\Xi}{\Xi} \\
\Xi\end{array}$} & $K_{\text {bare }}$ & 0.60 & $52 \%$ & 98 & 130 & $75 \%$ \\
\hline & $K_{i n f}, V_{\max }, C_{i n f}$ & 0.53 & $28 \%$ & 88 & 130 & $68 \%$ \\
\hline & $K_{\text {inf } f,} V_{\max }, C_{\text {bare }}$ & 0.56 & $27 \%$ & 92 & 130 & $71 \%$ \\
\hline & $K_{i n f}, V_{25 \%}, C_{i n f}$ & 0.95 & $29 \%$ & 143 & 130 & $110 \%$ \\
\hline & $K_{\text {inf }}, V_{25 \%}, C_{\text {bare }}$ & 1.19 & $24 \%$ & 173 & 130 & $133 \%$ \\
\hline
\end{tabular}

Table 9. Comparison between DBA and nonlinear dynamic analyses (DYN): $\mathrm{PGA}=0.74 \mathrm{~g}$.

\begin{tabular}{|c|c|c|c|c|c|c|}
\hline & & $\mu$ & $\xi_{e}$ & $\mathrm{DBA}[\mathrm{mm}]$ & $\mathrm{DYN}[\mathrm{mm}]$ & $\Delta_{\mathrm{DBA}} / \Delta_{\mathrm{DYN}}$ \\
\hline \multirow{5}{*}{ 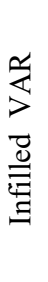 } & $K_{\text {bare }}$ & 1.12 & $49 \%$ & 151 & 177 & $85 \%$ \\
\hline & $K_{i n f}, V_{\max }, C_{i n f}$ & 0.78 & $29 \%$ & 109 & 177 & $62 \%$ \\
\hline & $K_{\text {inf }}, V_{\max }, C_{\text {bare }}$ & 0.82 & $28 \%$ & 114 & 177 & $64 \%$ \\
\hline & $K_{i n f}, V_{25 \%}, C_{i n f}$ & 1.45 & $30 \%$ & 193 & 177 & $109 \%$ \\
\hline & $K_{\text {inf }}, V_{25 \%}, C_{\text {bare }}$ & 1.51 & $29 \%$ & 201 & 177 & $114 \%$ \\
\hline \multirow{5}{*}{$\begin{array}{l}\text { 当 } \\
\text { 号 } \\
\text { 导 } \\
\stackrel{\equiv}{\Xi}\end{array}$} & Kbare & 1.28 & $47 \%$ & 185 & 202 & $92 \%$ \\
\hline & $K_{i n f}, V_{\max }, C_{i n f}$ & 0.96 & $30 \%$ & 145 & 202 & $72 \%$ \\
\hline & $K_{\text {inf }}, V_{\max }, C_{\text {bare }}$ & 1 & $29 \%$ & 149 & 202 & $74 \%$ \\
\hline & $K_{i n f}, V_{25 \%}, C_{i n f}$ & 1.28 & $47 \%$ & 231 & 202 & $114 \%$ \\
\hline & $K_{\text {inf }}, V_{25 \%}, C_{\text {bare }}$ & 1.66 & $30 \%$ & 237 & 202 & $117 \%$ \\
\hline
\end{tabular}




\section{LIST OF FIGURES}

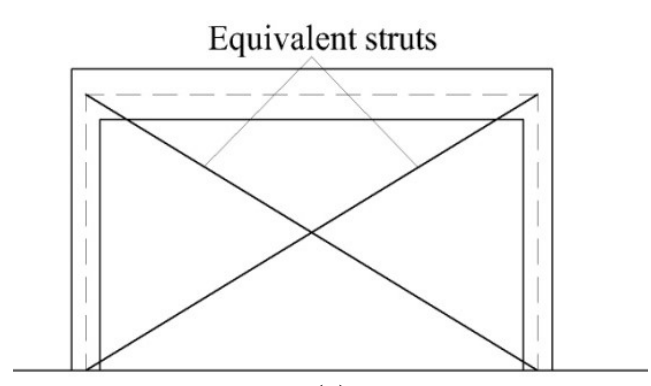

(a)

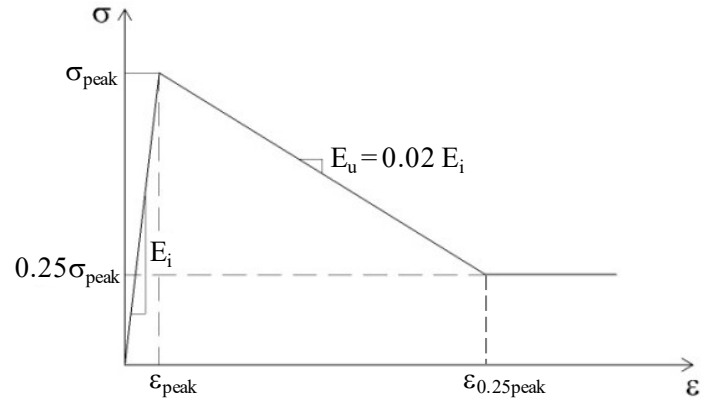

(b)

Figure 1. Equivalent diagonal struts (a) and stress-strain relationship assigned to the struts (b).
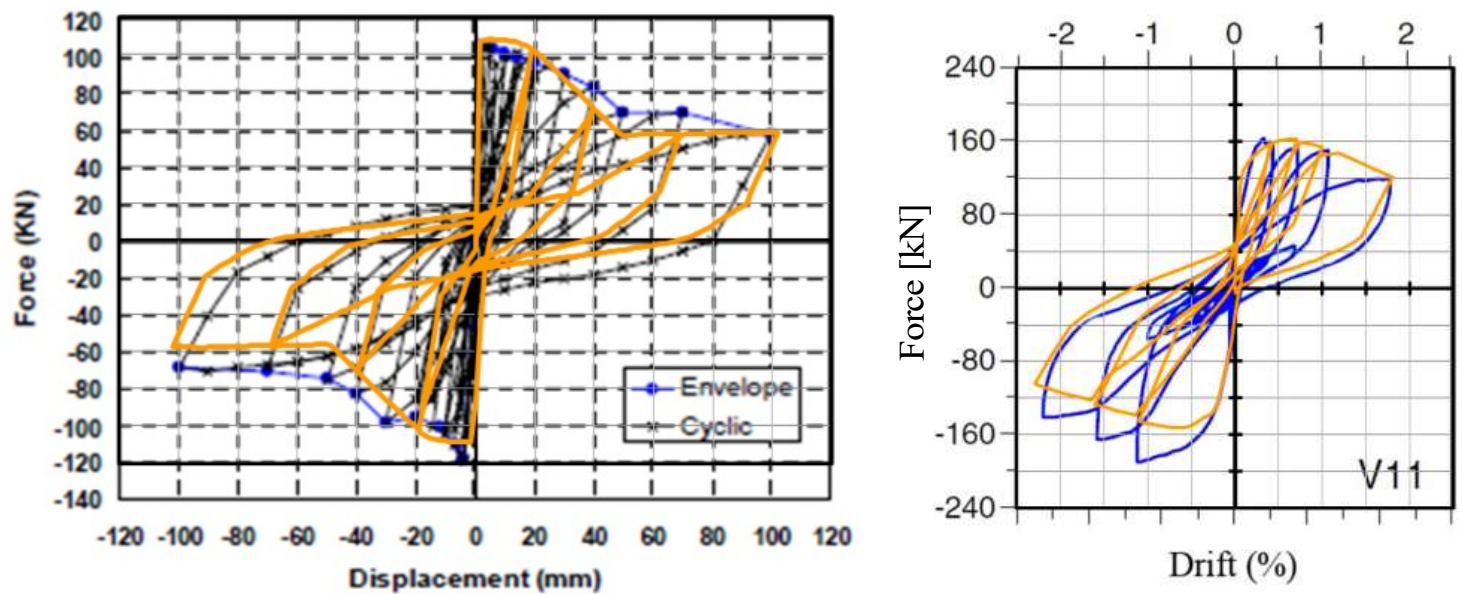

Figure 2. Comparison between numerical (orange curve) and experimental results (blue curve) for cyclic loading [Pires, 1990; Colangelo, 2004]. 


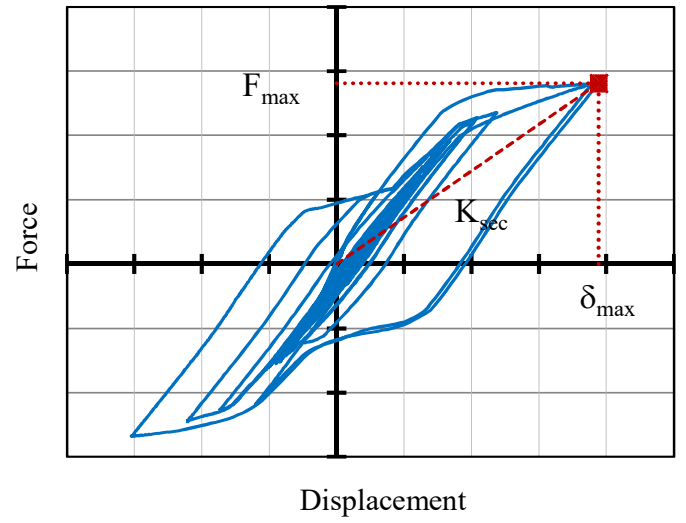

(a)

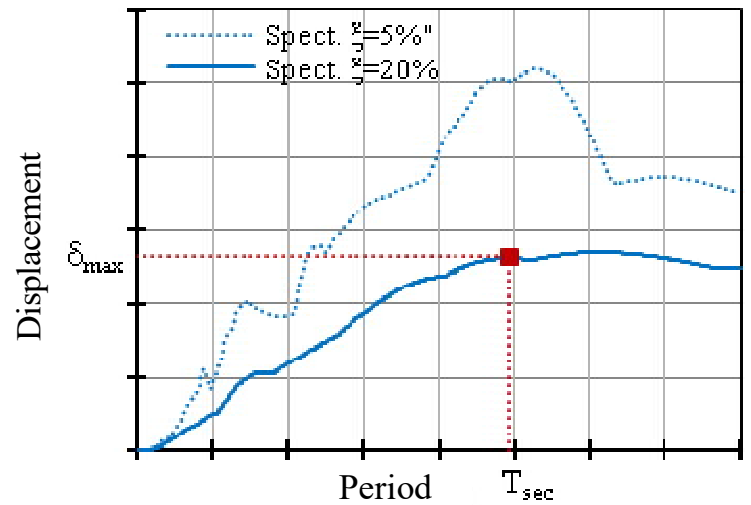

(b)

Figure 3. Graphic representation of the most important steps in the evaluation of equivalent damping: determination of secant stiffness (a) and reduced displacement spectrum (b).

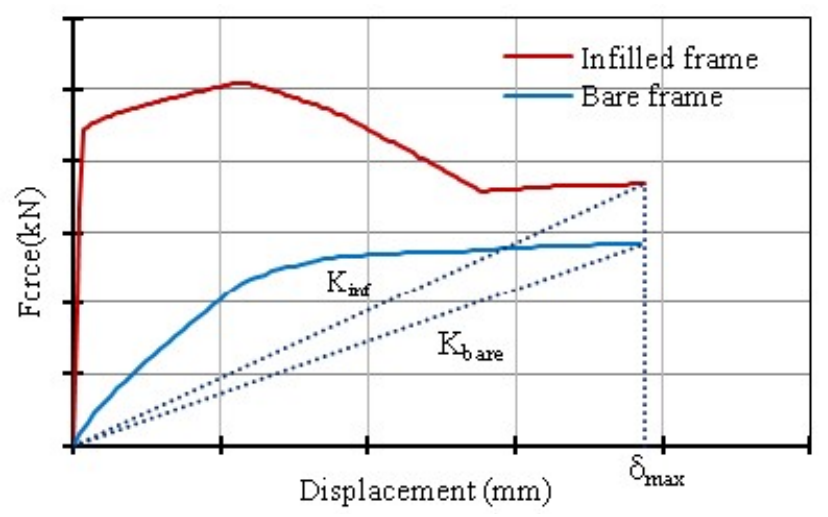

Figure 4. Secant stiffness of bare and infilled frames.

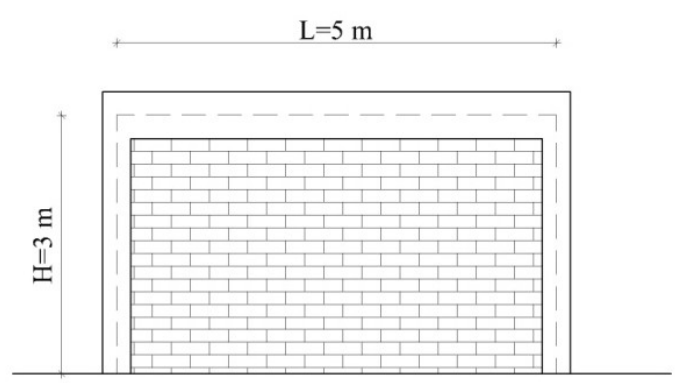

(a)

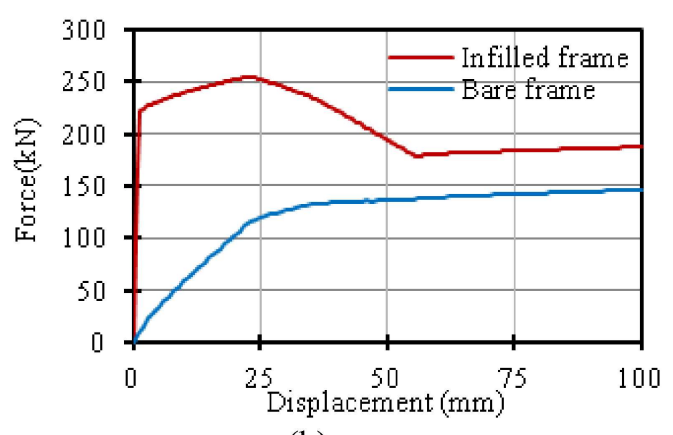

(b)

Figure 5. Geometrical configuration of single storey-single bay frames (a) and force displacement response of bare and infilled frames (b). 


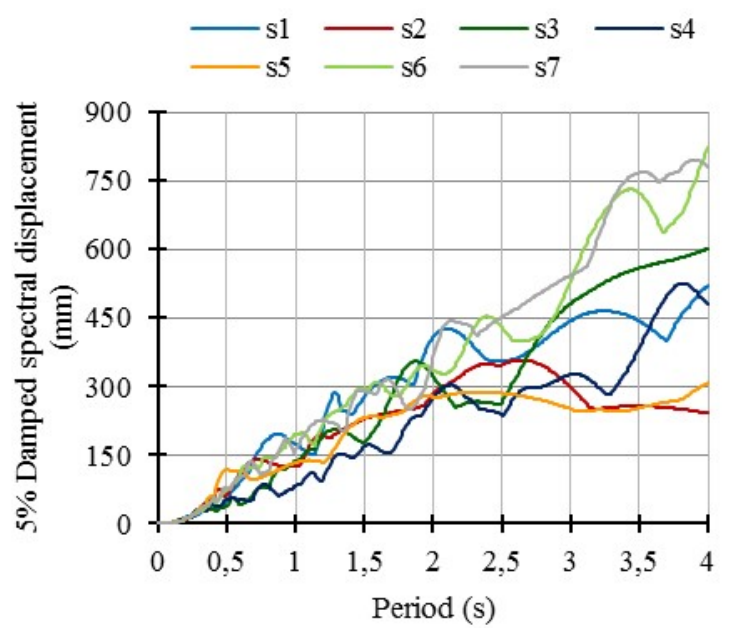

(a)

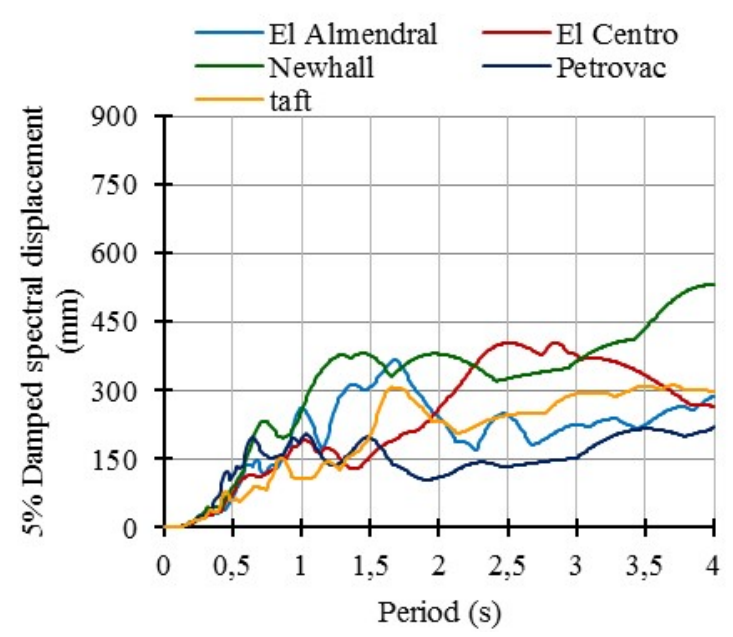

(b)

Figure 6. Displacement spectra for the two groups of ground motions scaled to PGA=0.5 g: Set_ 1(a),

Set_2(b).
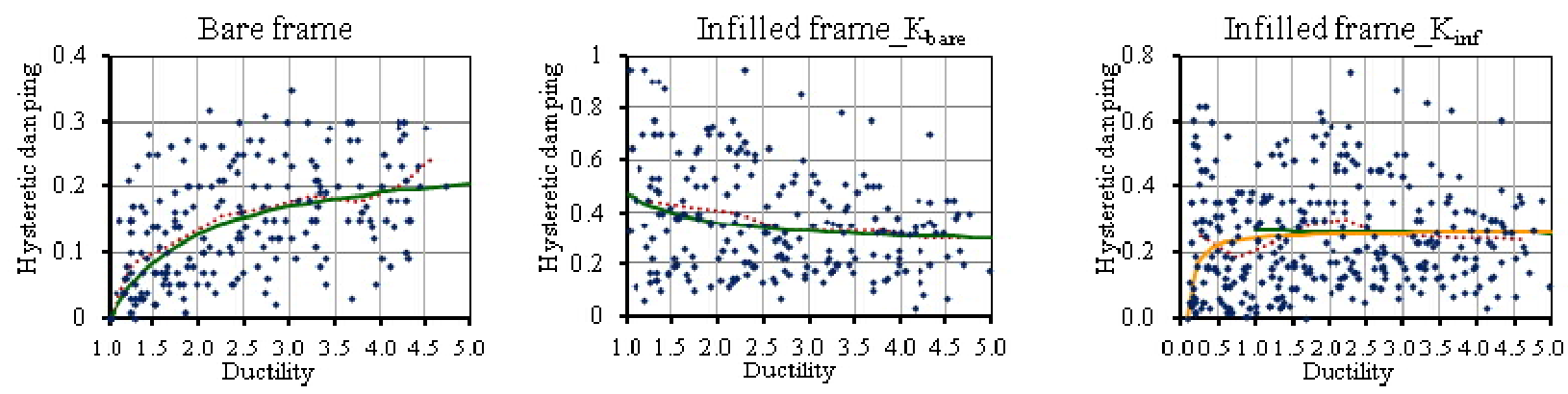

Figure 7. Ductility-damping values obtained from the analyses and average curves for all ground motions.

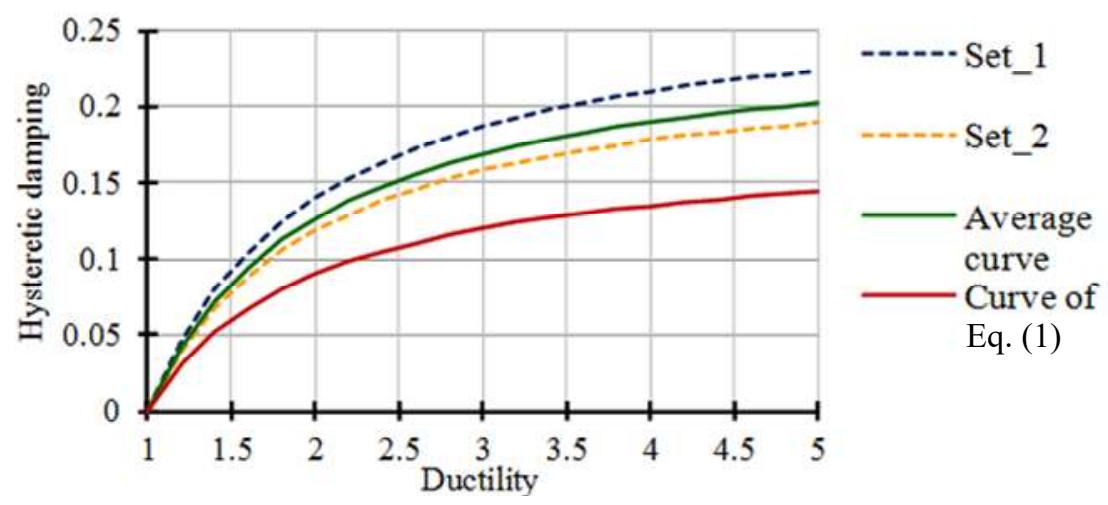

Figure 8. Average curves obtained for the bare frames compared with the curve of Eq. (1). 


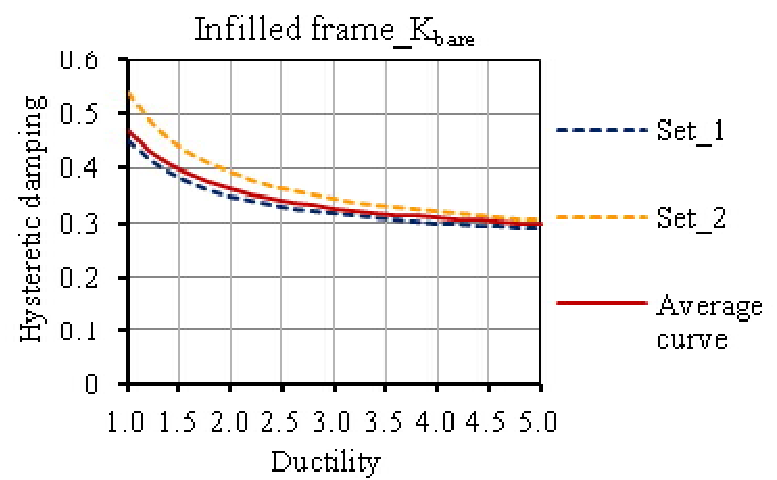

(a)

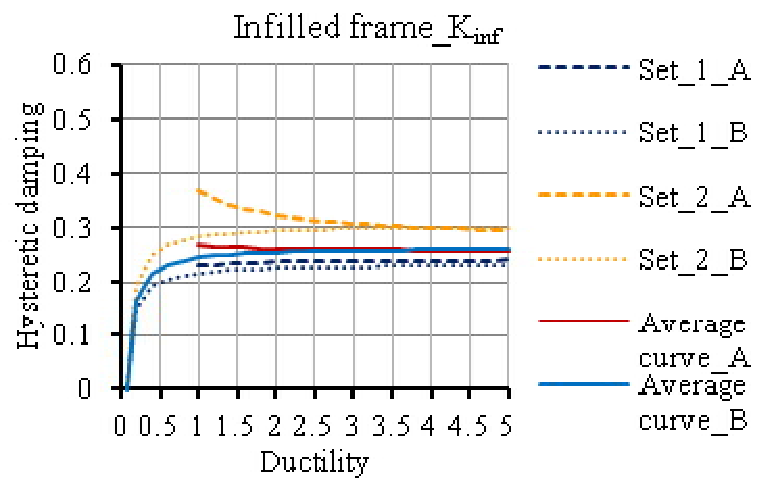

(b)

Figure 9. Average curves relative to the infilled frames obtained considering the stiffness of the bare frame (a) and the stiffness of the infilled frame (b).

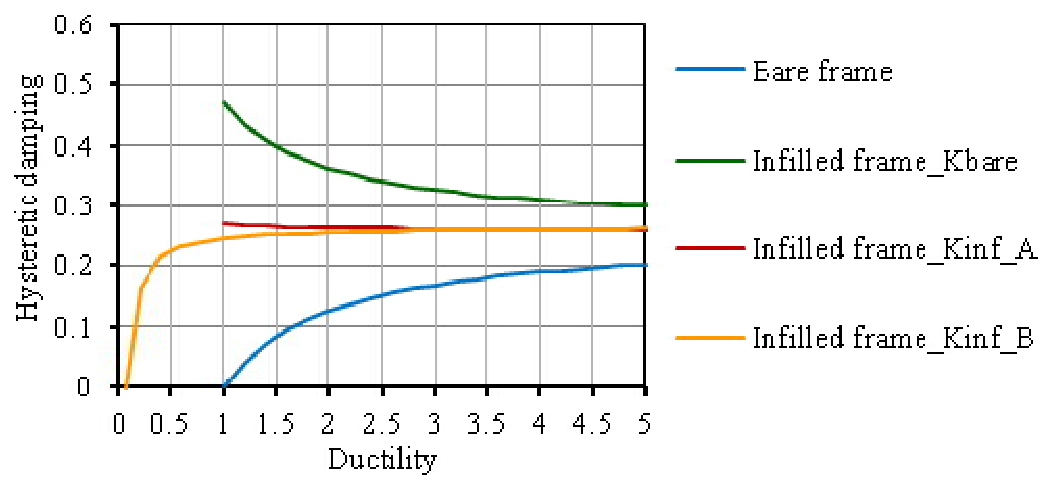

Figure 10. Overall average curves.

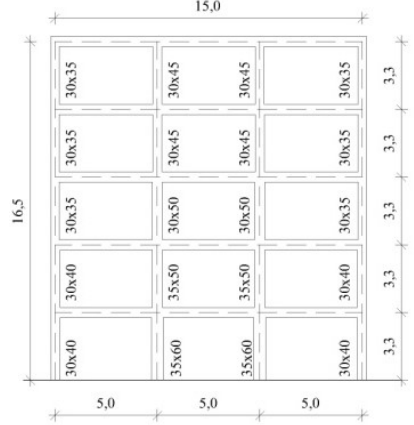

(a)

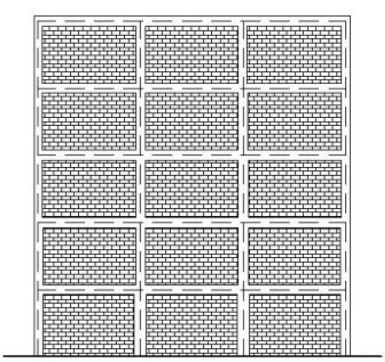

(b)

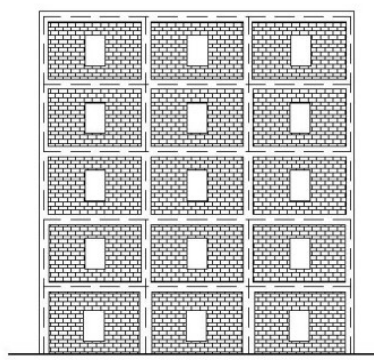

(c)

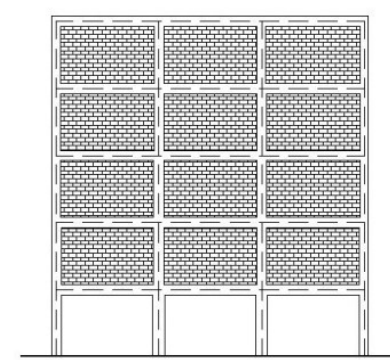

(d)

Figure 11. Representation of the examined frames: bare frame (a), totally infilled frame (b), totally infilled frame with openings (d) and infilled frame without panels at the ground floor (d). 

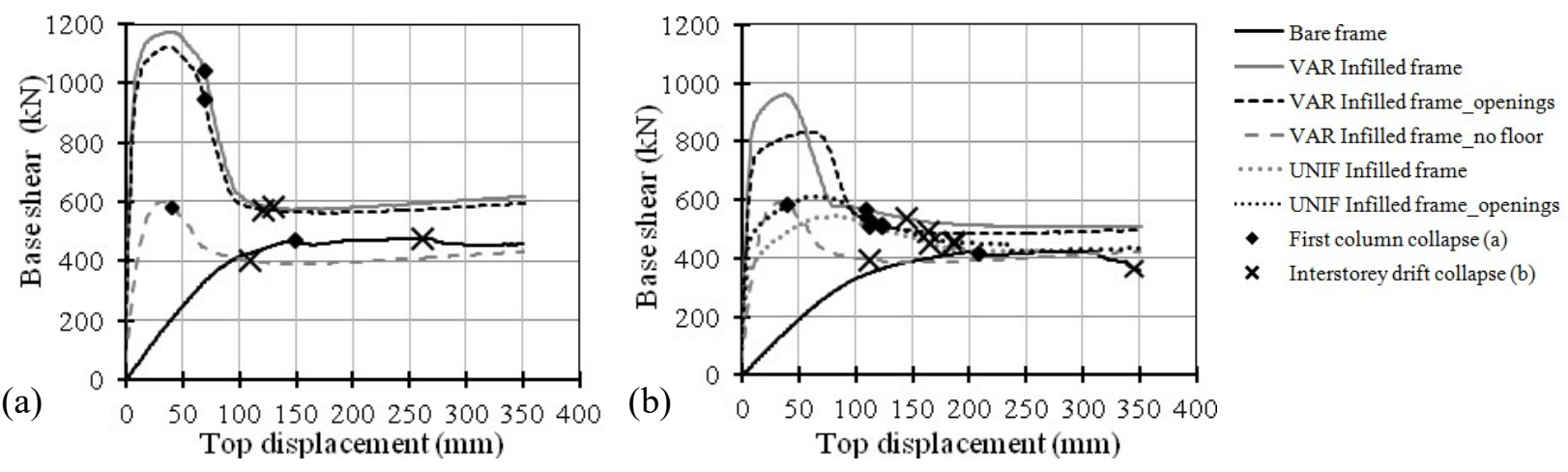

Figure 12. Pushover analyses: forces proportional to masses (a), forces proportional to the first mode (b).

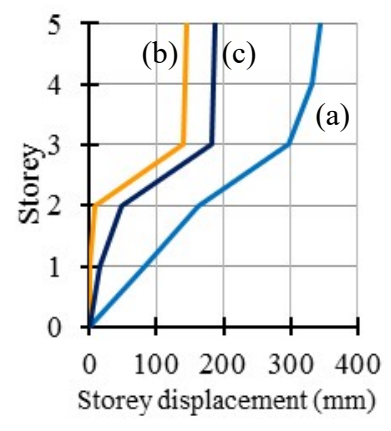

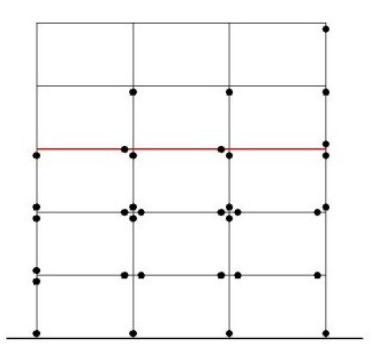

(a) Bare frame

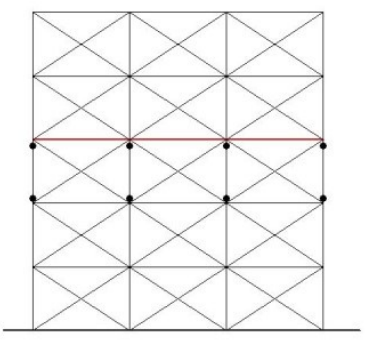

(b) Totally infilled frame VAR

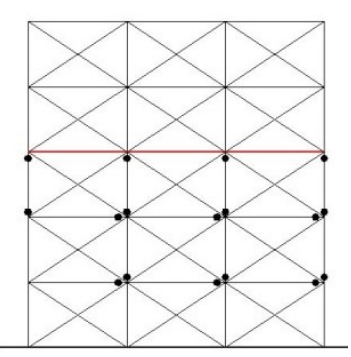

(c) Totally infilled frame UNIF

Figure 13. Displacement profile and distribution of plastic hinges under collapse condition "b" (achievement of ultimate inter-storey drift) in the case of forces proportional to the first mode. 

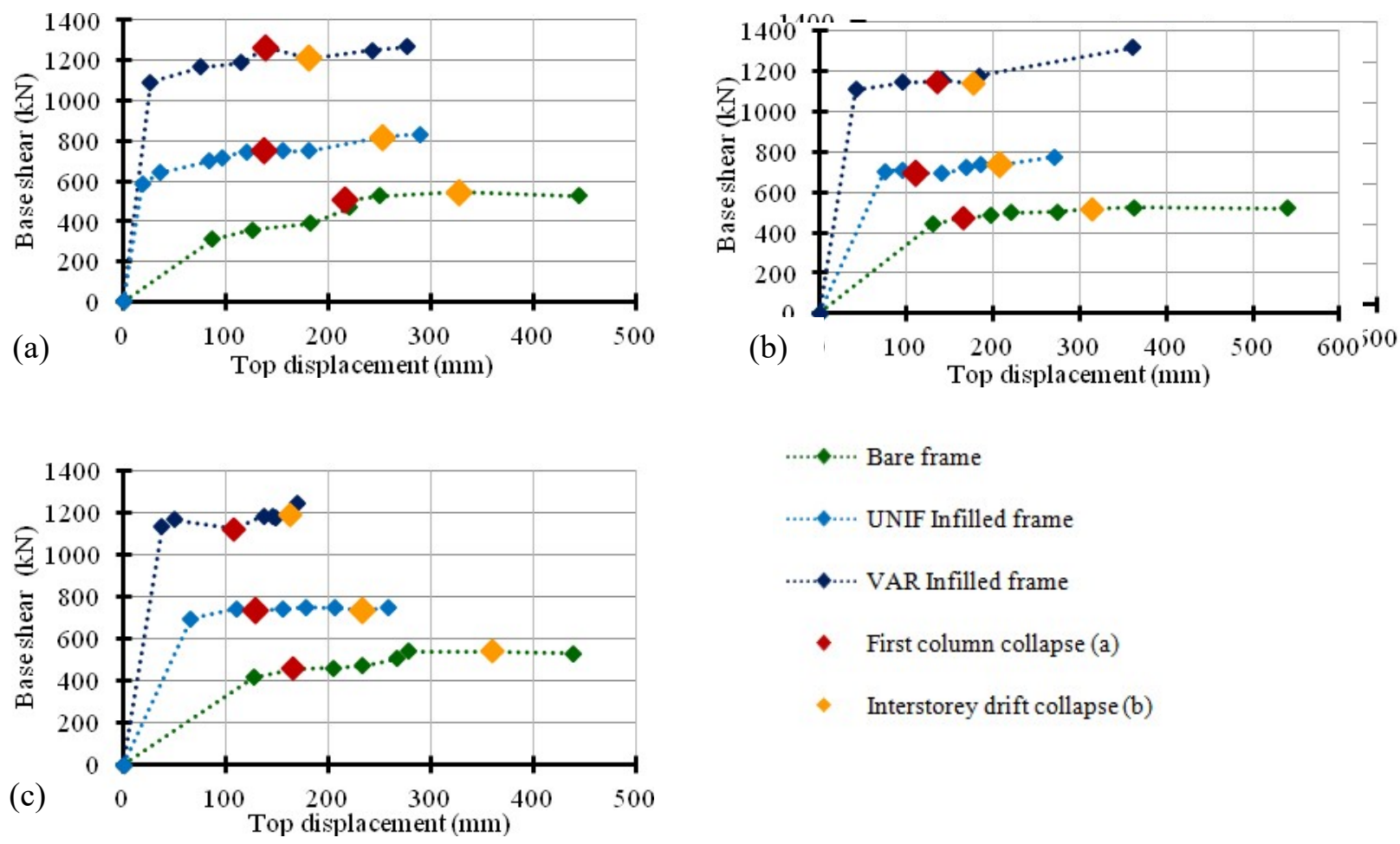

Figure 14. Top displacement-base shear curves from incremental dynamic analyses: S1 (a) S2 (b) S3 (c).

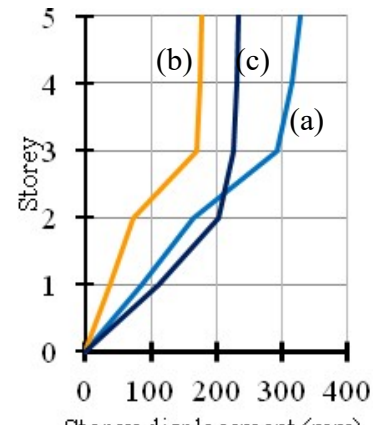

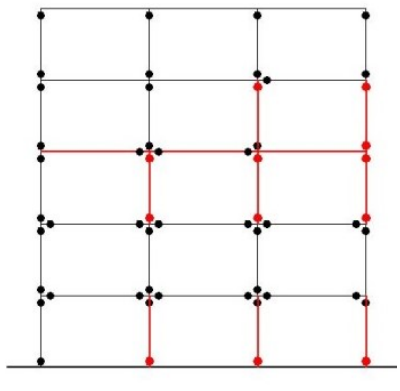

(a) Bare frame

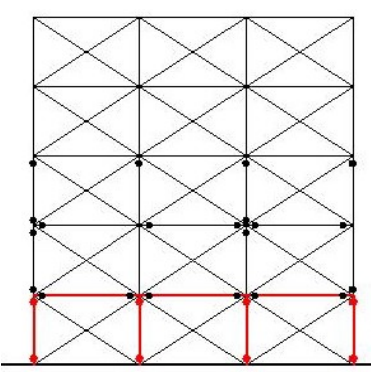

(b) Totally infilled frame VAR

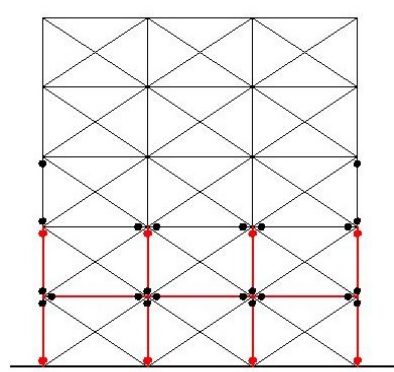

(c) Totally infilled frame UNIF

Figure 15. Displacement profiles and distribution of plastic hinges under collapse condition "b" for the ground motion $\mathrm{S} 1$. 


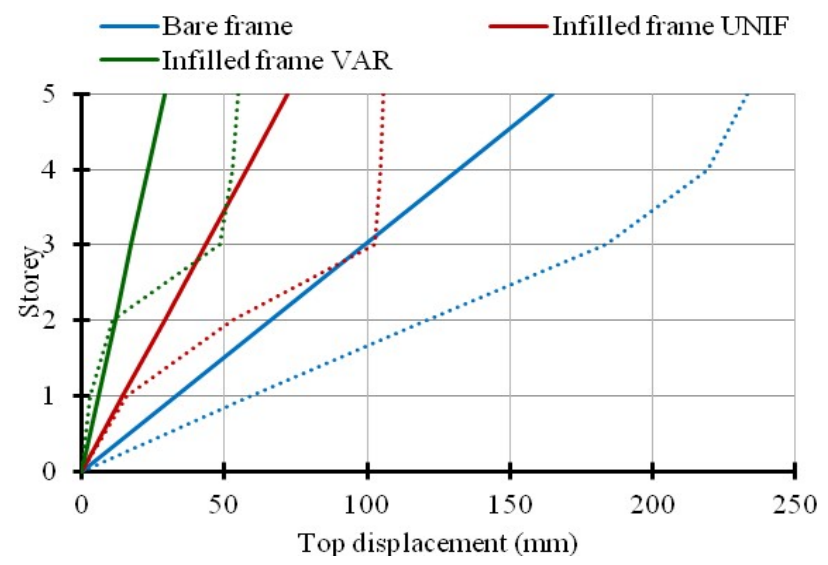

Figure 16. Yield displacement profile from pushover analyses (dot lines) and linearized (continuous lines).

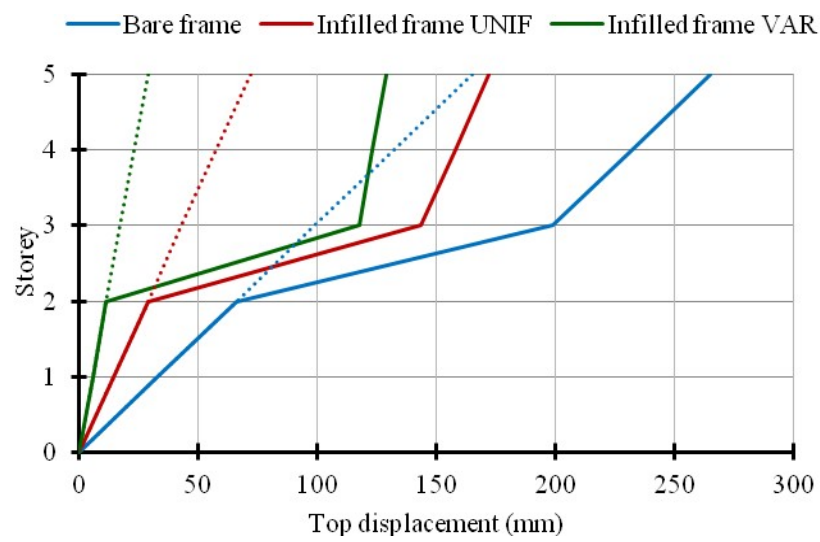

Figure 17. Limit-state displacement profiles (continuous lines) compared to yield displacement profiles (dotted lines).

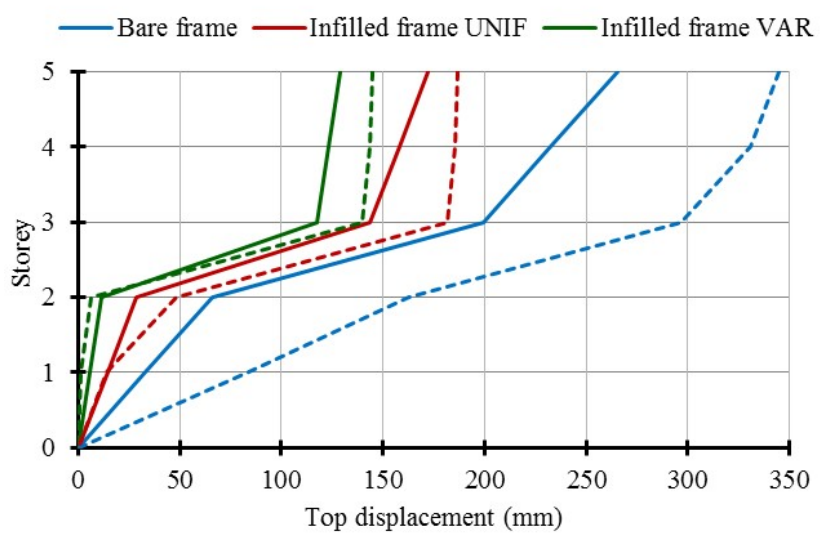

Figure 18. Limit-state displacement profile from pushover analyses (dot lines) and from proposed procedure (continuous lines). 


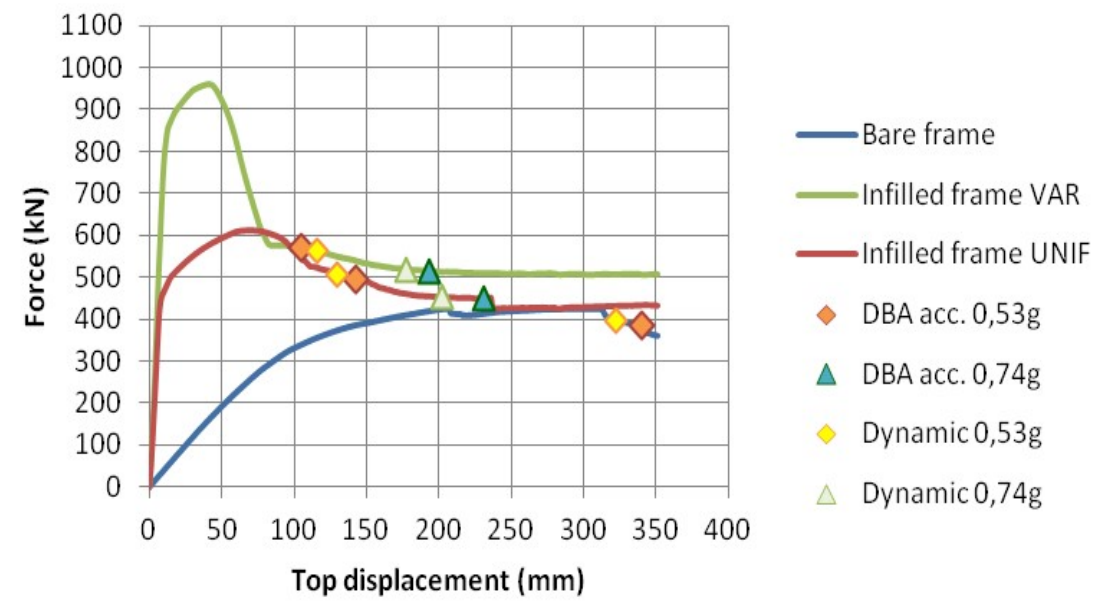

Figure 19. Comparison between DBA and nonlinear dynamic analyses: representation of the results in the pushover curves. 